\title{
Tidal fronts and their role in air-sea gas exchange
}

\author{
by B. Baschek ${ }^{1,2}$, D. M. Farmer ${ }^{1}$ and C. Garrett ${ }^{3}$
}

\begin{abstract}
Tidal fronts are a common feature of many coastal environments. They are characterized by a surface convergence zone that enhances wave breaking and the generation of gas bubbles due to wave-current interaction. The associated downwelling currents carry bubbles to depths of up to $160 \mathrm{~m}$ and increase the amount of air that dissolves from them.

An energetic tidal front is formed at the entrance to the Strait of Georgia, BC, Canada, by a hydraulically controlled sill flow with vertical velocities of up to $0.75 \mathrm{~m} \mathrm{~s}^{-1}$. Extensive ship-board measurements during two cruises are interpreted with models of wave-current interaction and gas bubble behavior. The observations suggest that tidal fronts may contribute significantly to the aeration of the subsurface waters in the Fraser Estuary. This process may be also of importance for other coastal environments with plunging sill flows of dense water that deliver aerated surface water to intermediate depths.
\end{abstract}

\section{Introduction}

Air-sea gas exchange plays a vital role in climate and has been the focus of continuing research, including observational and modeling studies. These studies have focused on the open ocean, although measurements are often conducted in more restricted environments such as lakes and in the laboratory where greater control can be exercised. There is, however, much interest in gas exchange in coastal waters - especially in densely populated areas where limiting dissolved oxygen conditions occur in subsurface waters.

The focus of this paper is on the mechanisms by which air can be entrained, dissolved, and subducted to substantial depths through tidally forced flow-topography interaction in passages connecting semi-enclosed basins with the open ocean. This interaction represents an interplay between the internal fluid dynamical behavior and the surface wave field, leading to wave breaking and bubble subduction. Although the active areas participating in this way are quite small, the influence on the aeration of the exchanging water mass can be significant.

1. Institute of Ocean Sciences, Sidney, British Columbia, Canada, V8L 4B2.

2. Present address: Marine Chemistry and Geochemistry, Woods Hole Oceanographic Institution, Woods Hole, Massachusetts, 02543, U.S.A.email: bbaschek@whoi.edu

3. School of Earth and Ocean Sciences, University of Victoria, Victoria, British Columbia, Canada V8W 2 YZ. 


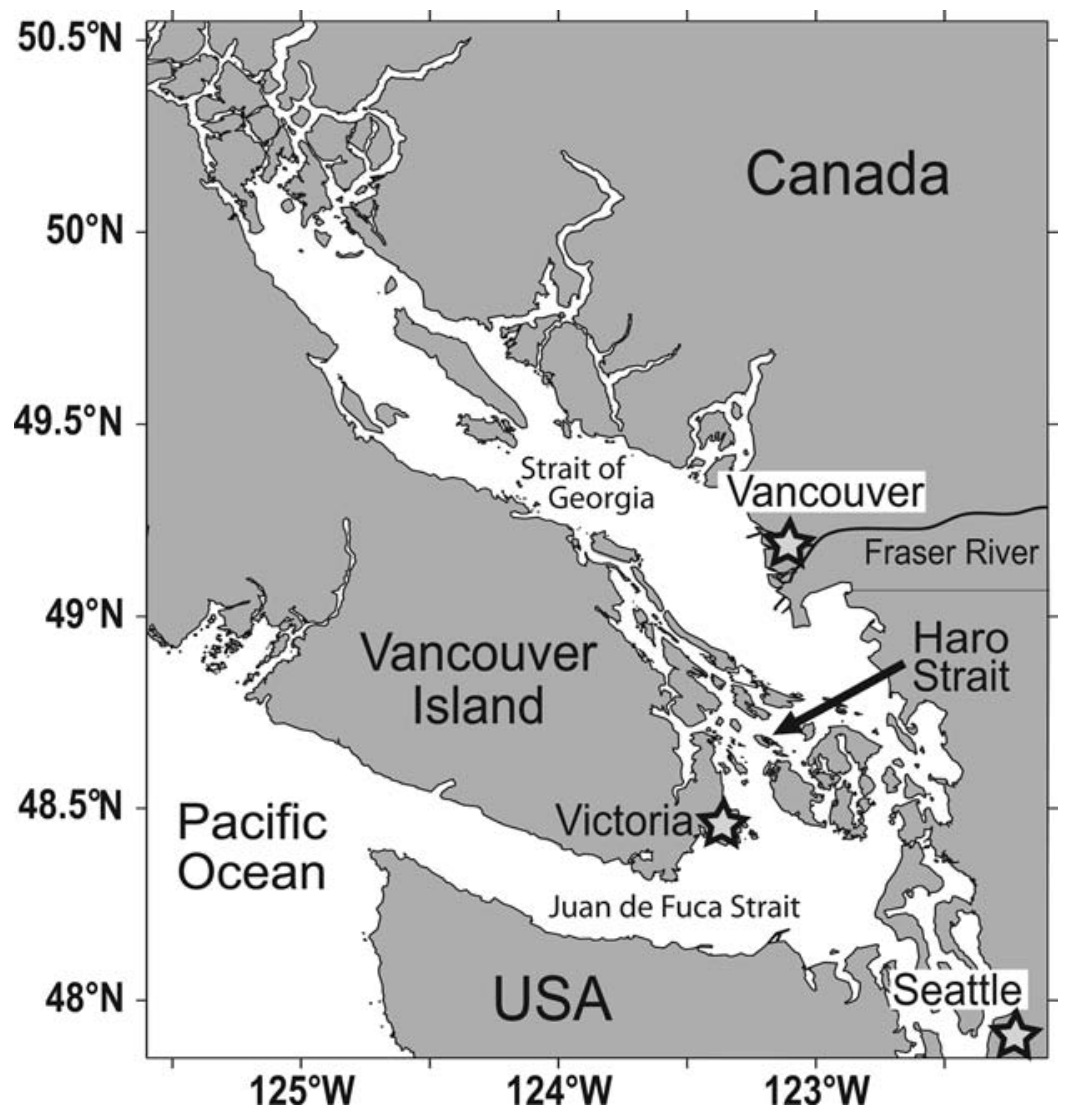

Figure 1. The Fraser Estuary in British Columbia, Canada.

The Fraser River estuary in British Columbia, Canada, (Fig. 1) is a highly productive ecosystem renowned for its salmon populations. Oxygen concentrations, however, can drop in the Strait of Georgia to levels below 2-4 $\mathrm{mL} \mathrm{L}^{-1}$ (Crean and Ages, 1971; D. Masson, IOS, Canada, pers. communication; Fig. 2) at which fish are affected negatively (Müller and Stadelmann, 2004). The ventilation of the Strait of Georgia is controlled by a sill at its entrance (Boundary Pass) that forms a pronounced barrier to flow through the Strait and causes intense mixing. It is suggested that the mechanisms that supply oxygen to the subsurface waters are as follows: interaction of strong tidal currents with topography mixes dense water from the Pacific Ocean with relatively fresh, oxygenated surface water. This water is further aerated by the generation and subduction of gas bubbles in the tidal fronts of Haro Strait. At Boundary Pass, it flows over a sill to intermediate depths, from where the oxygen is likely to be transported by diffusion to the deeper parts of the Strait. During the rare deep water renewal events, oxygen can be also delivered directly to the deep water in the Strait of Georgia (LeBlond et al., 1991; Masson, 2002). 


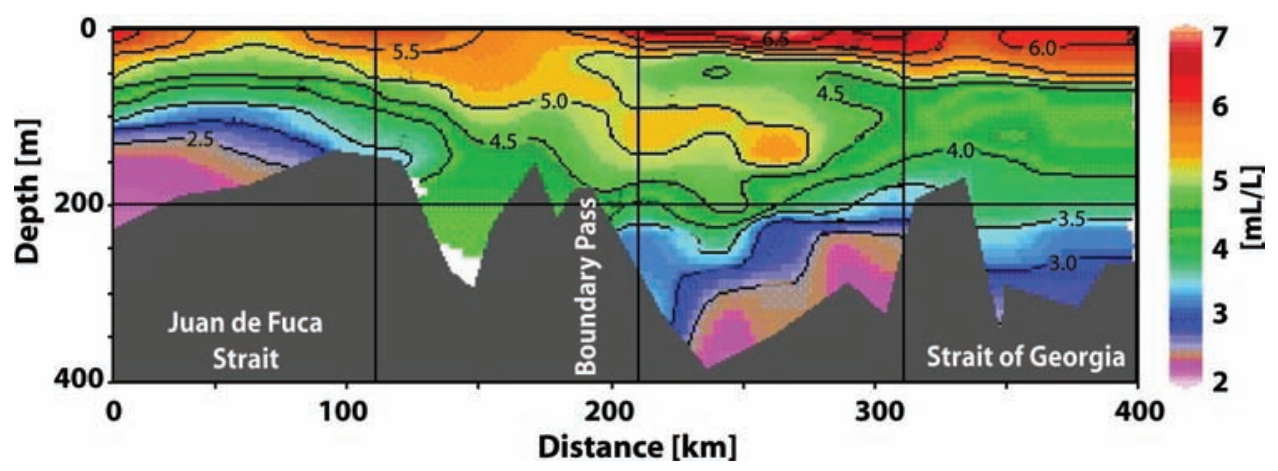

Figure 2. Oxygen section along the Fraser Estuary in July 2000 (D. Masson, IOS, Sidney, Canada). The Pacific Ocean is to the left, the Strait of Georgia to the right, and the sill at Boundary Pass at $x=180 \mathrm{~km}$.

Keeling (1993) suggests that bubbles make an important contribution to air-sea gas exchange in the open ocean at wind speeds above $10 \mathrm{~m} \mathrm{~s}^{-1}$, and bubble plumes are commonly observed down to 10-15 m (Vagle, 1989; Crawford and Farmer 1987; Wallace and Wirick, 1992). In tidal fronts, however, gas bubbles are also injected into the ocean on calm days as a consequence of the amplification of small waves in adverse currents. Bubble clouds can reach depths up to $160 \mathrm{~m}$ in the present situation.

The objectives of this paper are to understand the physical processes relevant for the generation and entrainment of gas bubbles in tidal fronts and to estimate their contribution to air-sea gas exchange. First, we present measurements of the hydraulically controlled sill flow at Boundary Pass that forms an energetic tidal front over the sill crest. Wave breaking and the injection and dissolution of gas bubbles are calculated for this front with models of wave-current interaction and gas bubble behavior. This leads to an estimate of the contribution of this and other tidal fronts to the aeration of the Fraser Estuary. This contribution is then compared to other oxygen sinks and sources. It is finally shown that the physical processes described here may also be relevant to the coastal ocean in other parts of the world.

\section{Instrumentation}

Two research cruises were carried out with the research vessel CCGS Vector in Haro Strait and Boundary Pass in October 1999 and September 2000. Measurements were taken with an ADCP, an echo sounder, a CTD, and an Acoustical Resonator for measuring bubble size distributions.

The $150 \mathrm{kHz}$ workhorse ADCP from RDI was mounted on a strut on the side of the vessel at a depth of $1 \mathrm{~m}$. The instrument has a bandwidth of $39 \mathrm{kHz}$ and a beam angle of $20^{\circ}$. Bottom tracking was used to convert the data from ship-coordinates to earth-coordinates allowing for a direct correction of the alignment angle. The ship's position and heading were provided 
by a differential GPS-receiver and a flux gate compass. Measurements were taken every $1 \mathrm{~s}$ and averaged to create $10 \mathrm{~s}$ ensembles. With a bin size of $4 \mathrm{~m}$, the ADCP measured the upper 200-300 $\mathrm{m}$ of the water column. In spite of the strong horizontal current gradients the standard 4-beam solution can be used to calculate the current speed (Baschek, 2003).

The acoustic backscatter intensity of the water column was measured with a $100 \mathrm{kHz}$ echo sounder. The transducer was mounted in the hull of CCGS Vector at a depth of $2 \mathrm{~m}$. The receiver band width was set to $5 \mathrm{kHz}$, the transmission interval to $0.5 \mathrm{~s}$, and the pulse width to $0.3 \mathrm{~ms}$. An Acoustical Resonator was used for measuring bubble size distributions in the tidal fronts (Farmer et al., 1998). With a frequency range of 6-196 kHz, gas bubbles with radii of $15-550 \mu \mathrm{m}$ can be detected. The Seabird SBE-19 CTD was calibrated prior to the cruises. Salinity samples were taken from different depths for recalibration after the cruises.

Measurements in the tidal fronts were carried out at ebb and flood tide. In order to minimize the ship's speed through the water to reduce the wire angle, repeated profiles were acquired with the CTD or Acoustical Resonator while the ship traveled in the direction of the currents. Additional CTD stations were carried out for hydrographic background measurements. Repeated profiles using the Acoustical Resonator in the upper $60 \mathrm{~m}$ were carried out while the ship remained stationary in the tidal front. These measurements were repeated several times over a tidal period to map the temporal evolution of the front. In order to minimize spring-neap tidal variations, the two cruises were carried out at a time when the tidal currents were of similar amplitude.

\section{Tidal fronts}

Tidal fronts can be defined as sharp transition zones between two water masses of different density and (tidal) current speed. They are characterized by converging flow at the sea surface, which causes enhanced wave breaking and the formation and subduction of gas bubbles. Their surface expressions are clearly visible at the sea surface. Tidal fronts can be formed by three different mechanisms: inflow of dense water from an adjacent channel, flow separation past a headland (Farmer et al., 2002), or flow over a shallow sill. The observations from the Fraser River estuary described here are of the latter type.

The Fraser River delivers a mean discharge of $4,400 \mathrm{~m}^{3} \mathrm{~s}^{-1}$ to the estuary (Thomson, 1994). This water flows at the surface through Haro Strait and Juan de Fuca Strait into the Pacific Ocean, while beneath it, saltier and denser water enters the estuary from the Pacific Ocean. Superimposed on this mean circulation is a strong tidal regime with pronounced spring-neap tidal variability (Pawlowicz, 2002), which causes intense flow-topography interaction and mixing (Pawlowicz and Farmer, 1998; Farmer et al., 1995).

At Boundary Pass, a steep sill is located between Saturna and Patos Island (Fig. 3) and forms a pronounced barrier for the water exchange between Haro Strait and the Strait of Georgia. With a mean slope of about $30^{\circ}$, it rises from $200 \mathrm{~m}$ to $60 \mathrm{~m}$ depth and also blocks about $80 \%$ of the width of the passage. At flood tide, a hydraulically controlled flow 


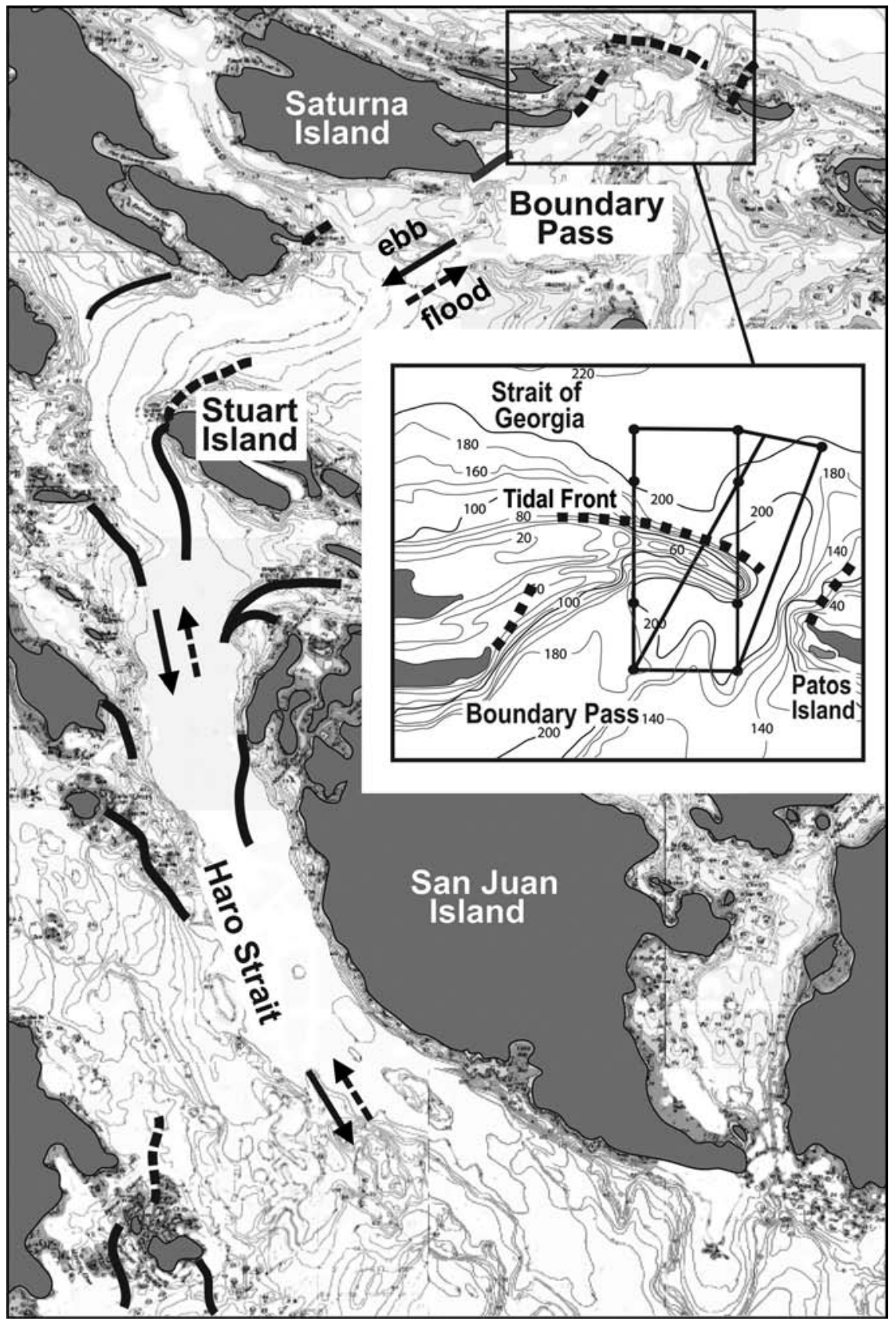

Figure 3. Chart of Haro Strait and Boundary Pass. The solid lines and arrows indicate the approximate locations of tidal fronts and flow direction during ebb tide, the dashed lines during flood tide. The small map shows the measurement transects at the sill at Boundary Pass. 
develops over the sill and delivers oxygen rich water to intermediate depths of 150-250 m. Its forcing changes significantly during the flood tide. The moderate to intermediate and strong forcing (Farmer and Armi, 1986) and an additional stage of flow separation during extreme forcing have been observed. During strong and extreme forcing, extensive gas bubble clouds are entrained into the ocean enhancing air-sea gas exchange. Both of these stages are discussed below.

\section{a. Strong forcing}

At $0.5-1.5 \mathrm{~h}$ after the ebb slack tide, the sill flow at Boundary Pass is strongly forced. Dense water flows from Boundary Pass over the sill into the Strait of Georgia. Just downstream of the sill crest, this water meets an arrested surface layer with relatively fresh water and subducts beneath it due to the density difference between the two water masses (Fig. 4a). At the surface, a distinct $50 \mathrm{~m}$ wide tidal front line forms. It stretches from the south-eastern tip of Saturna Island to the end of the sill close to Patos Island. The flow is in the uncontrolled state and the location of the plunge point depends only on the bathymetry, the strength of the barotropic forcing, and the relative density difference to which it constantly adjusts (Armi and Farmer, 2002).

An example of strongly forced flow is shown in Figure 5. It provides a quasi-synoptic picture of the flow field, as it took only 6 min to complete this part of the transect, while the time scale over which the tidal currents change is $\sim 2 \mathrm{~h}$. The dark red line of high backscatter intensity indicates the sea floor (A). The red/orange area just above it (B) corresponds to the sonar side lobe interaction with the sea floor and limits the depth of useful Doppler measurements. The high backscatter intensities extending from the sea surface to about $105 \mathrm{~m}$ depth (C) indicate mostly gas bubbles, as verified by independent measurements with an Acoustical Resonator. The bubbles are injected close to the lower layer plunge point and are carried down along the interface between upper and lower layer by strong vertical velocities of up to $0.75 \mathrm{~m} \mathrm{~s}^{-1}$.

The horizontal component within the dense overflow reaches $2.2 \mathrm{~m} \mathrm{~s}^{-1}$ at the sill crest and $1.7 \mathrm{~m} \mathrm{~s}^{-1}$ towards the bottom of the sill and prior to the transition to an internal hydraulic jump. The strong lower layer currents are mainly orthogonal to the isobaths while the upper layer currents are weak with variable flow directions. A comparison of the measurements at the sill crest and bottom of the sill show that the flow exchange across the shear layer is about $60 \%$ of the lower layer flow (Baschek, 2003), i.e. $60 \%$ of the flow has been entrained into the upper layer and $40 \%$ carries on. At the plunge point, the density difference between the two water masses is $2.7 \mathrm{~kg} \mathrm{~m}^{-3}$.

The hydraulic sill flow and tidal front have significant influence on the aeration of intermediate water in the Strait of Georgia. At flood tide, dense water mixes with aerated surface water and delivers oxygen to subsurface waters. It usually subducts to $150-200 \mathrm{~m}$, but can also ventilate the deep water during the rare deep water renewal events (Masson, 2002). The water is further aerated by gas bubble injection in the tidal front. The vertical component of 

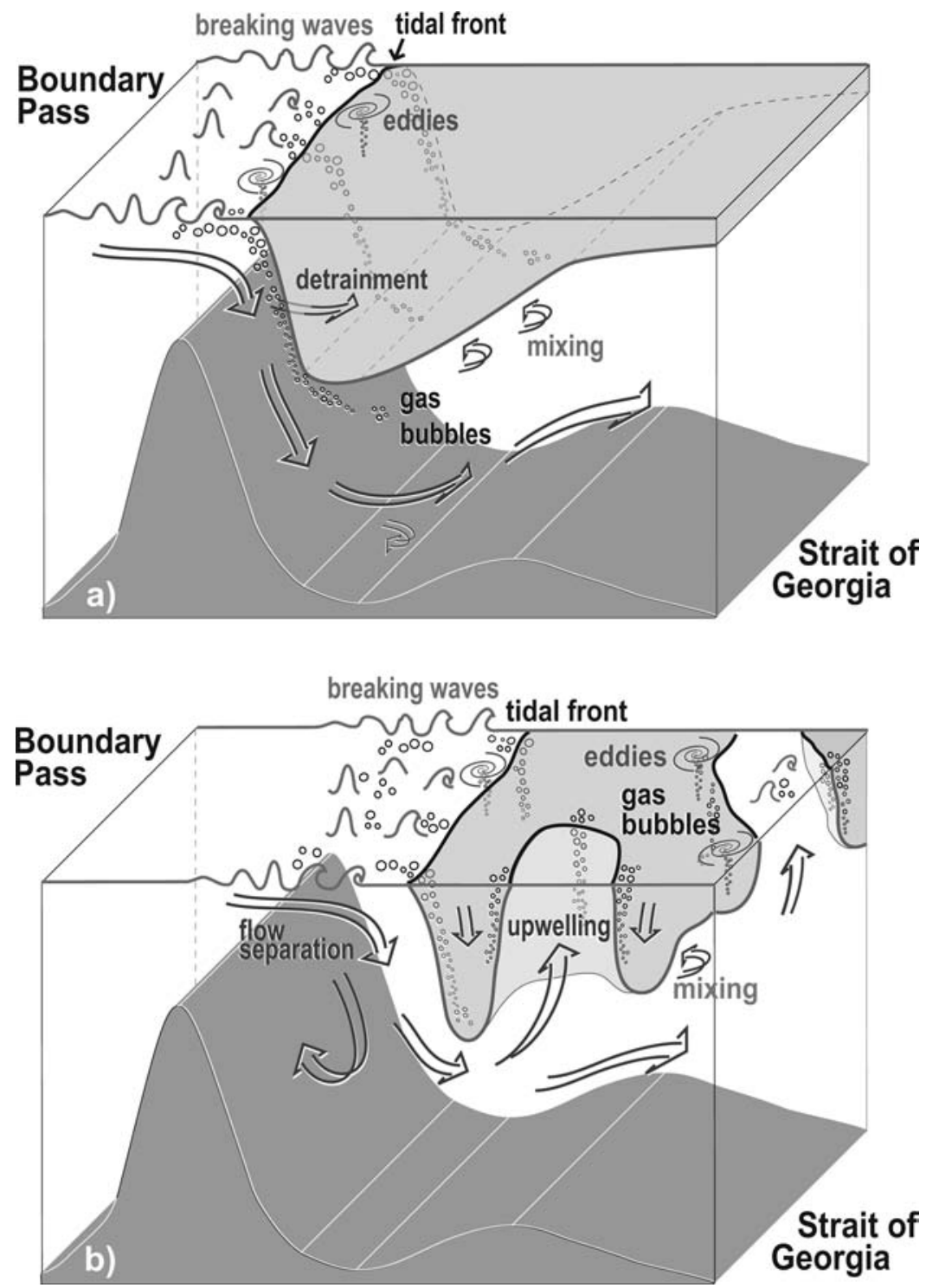

Figure 4. Sketch of the processes that are important for air-sea gas exchange in the tidal front at Boundary Pass during (a) strong forcing and (b) extreme forcing.

the velocity in the front is $0.15-0.3 \mathrm{~m} \mathrm{~s}^{-1}$, which exceeds the rise speed of all bubbles with radius $<900 \mu \mathrm{m}$. Bubbles trapped in the downwelling currents are drawn into the deeper water where they dissolve. If we assume that they go into dissolution in the same volume, the dissolved oxygen concentration (in $\mathrm{mLL}^{-1}$ ) would increase by $2 \cdot 10^{2}$ times the void fraction of the injected bubbles, giving a sense of their contribution to aeration. 


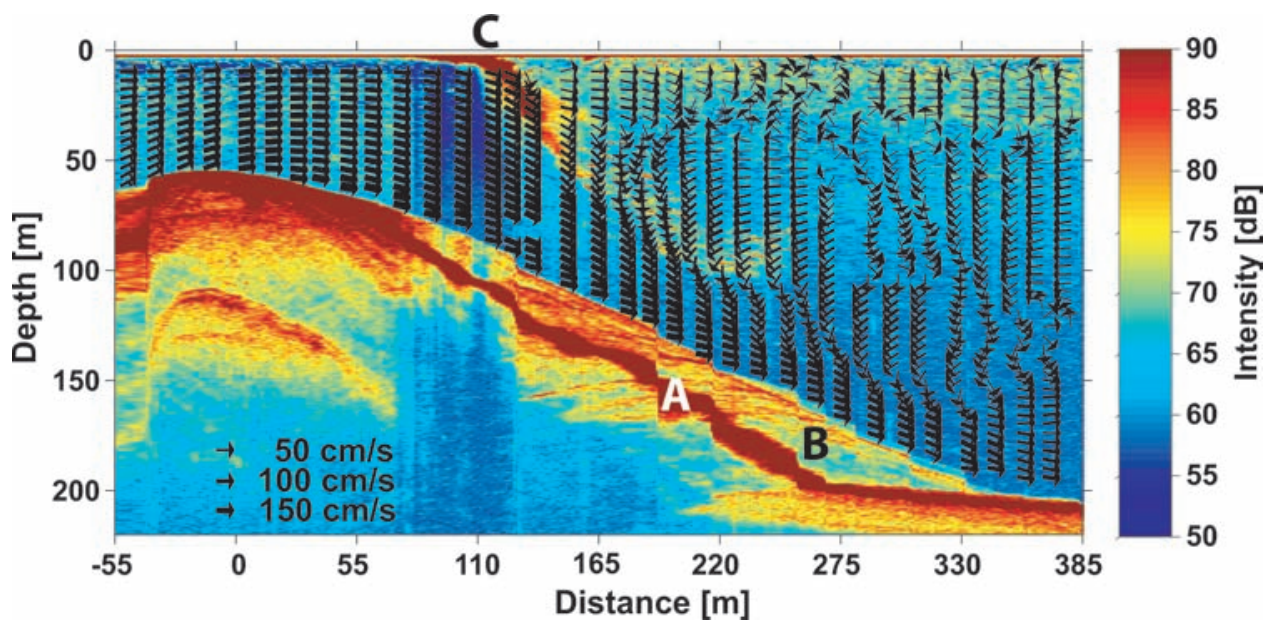

Figure 5. Flow over the sill at Boundary Pass during strong forcing on September 29, 2000. The colors show the acoustic backscatter intensity measured with an echo sounder and the black arrows indicate the current speed perpendicular to the sill crest. The aspect ratio is 1:1.

\section{b. Extreme forcing}

When the tidal forcing increases further (2.5-4.5 $\mathrm{h}$ after low tide), the flow shoots over the sill as a supercritical inertial jet with flow separation at the sill crest (Fig. 4b, 6). The lower layer plunge point is shifted far downstream by the currents and is no longer delineated by a clear front. The flow field downstream of the sill crest is characterized by irregular 3-dimensional convergence/divergence patterns associated with strong eddy activity and wave breaking. Gas bubble clouds - indicating downwelling currents - are spread over a distance of about $2 \mathrm{~km}$, starting several hundreds of meters downstream of the sill.

The contribution to the aeration of water locally is still significant, even though the vertical currents $\left(0.25-0.3 \mathrm{~m} \mathrm{~s}^{-1}\right)$ are much weaker. However, due to dilution through intense mixing it is likely that the aerated water at this stage is insufficiently dense to reach intermediate depths and bubble injection does not contribute to the aeration of subsurface waters.

\section{Wave-current interaction in a convergence zone}

In the convergence zone of a tidal front, either both water masses flow towards the front or one of them is stagnant. Surface gravity waves that travel into this zone steepen due to the effect of the opposing currents, break, and create gas bubbles that enhance air-sea gas exchange as may be readily seen in Figure 7. In order to estimate the amount of gas entrained, the injection location of the gas bubbles relative to the plunge point of the subducting flow has to be determined. It is given by the interaction of waves and currents. A model that describes the behavior and energy dissipation of waves traveling on a current is found in detail in Baschek (2005) and will be reviewed here briefly. 


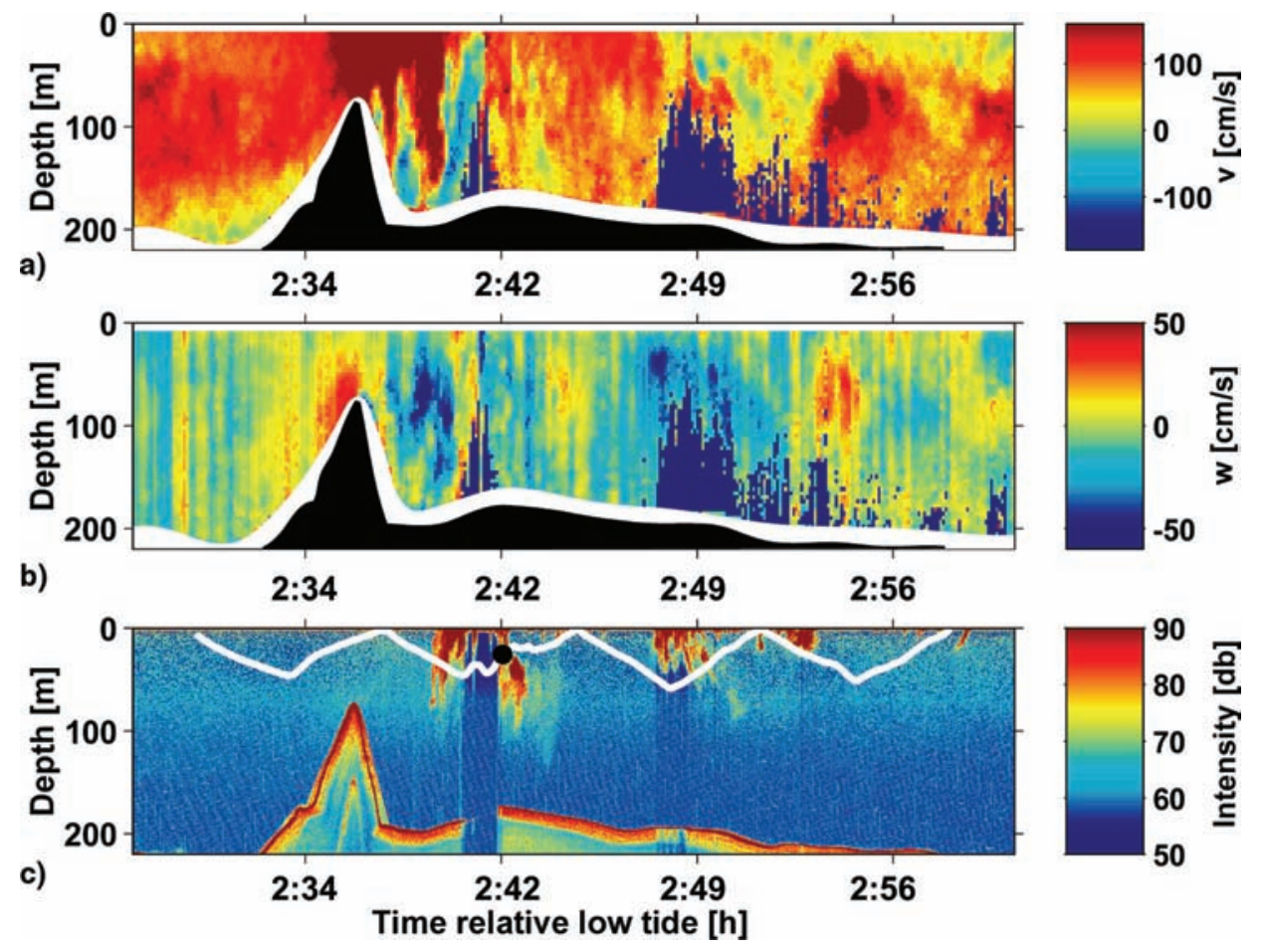

Figure 6. Transect over the sill at Boundary Pass during extreme forcing measured with an ADCP, an echo sounder, and a towed Acoustical Resonator on September 29, 2000. (a) Along-strait current; (b) vertical current; (c) acoustic backscatter intensity. The path of the resonator is shown by the white line and the location of the bubble measurements in Figure 17 by the black dot.

Bretherton and Garrett (1969) derived a conservation equation for wave action, that is valid for waves on a slowly varying current, i.e. the current changes only little over a wave length. For a steady wave train traveling in the $x$-direction it can be written as

$$
\frac{d}{d x}\left\{\left(u+c_{g}\right) \frac{E}{\omega^{\prime}}\right\}=0,
$$

where $u$ and $c_{g}$ are the current speed and group velocity. $E$ is the wave energy, $\omega^{\prime}$ the wave frequency relative to the water. For deep water waves, using $\omega^{\prime}=g / c$ and $c_{g}=c / 2$,

$$
E\left(u+\frac{1}{2} c\right) c=\text { const } . \equiv \frac{1}{2} E_{0} c_{0}^{2},
$$

where the subscript " 0 " marks variables in a medium at rest. This yields together with the wave energy $E=\rho g a^{2} / 2$ an expression for the wave amplitude (Phillips, 1977)

$$
\frac{a}{a_{o}}=\frac{c_{0}}{\sqrt{(2 u+c) c}}
$$




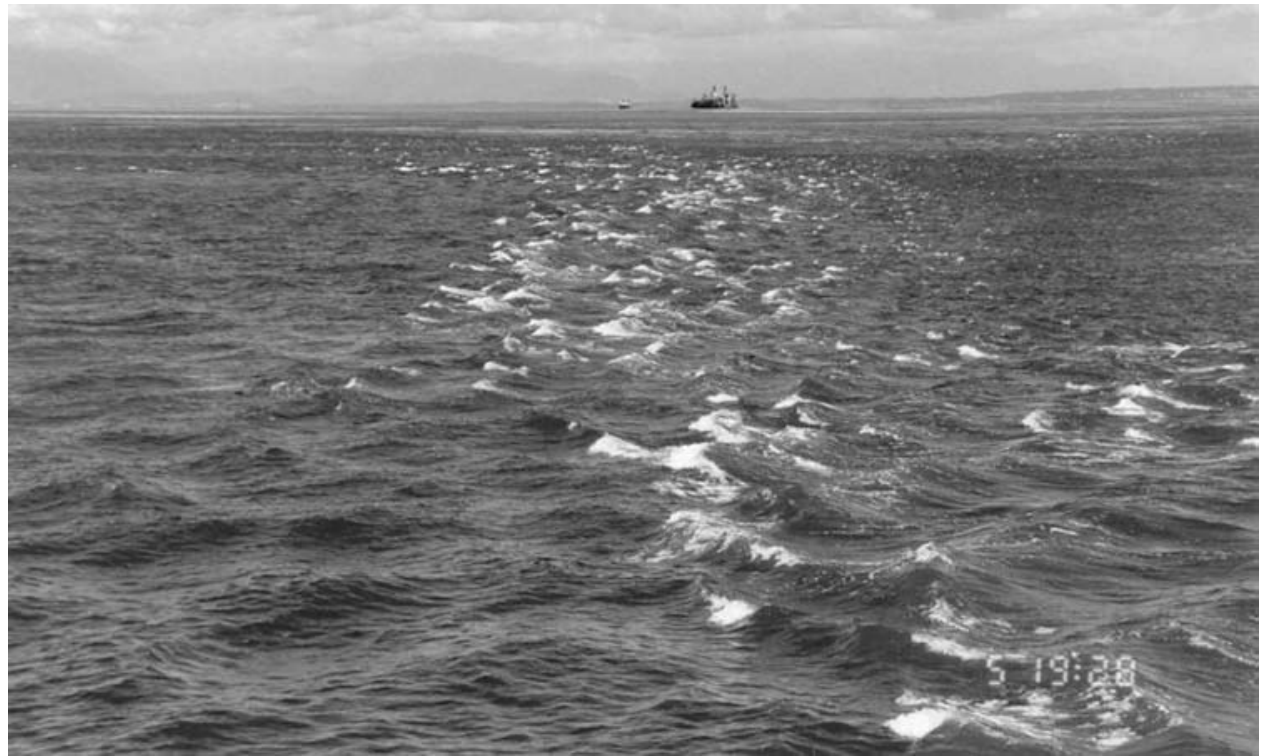

Figure 7. Wave breaking due to wave-current interaction in the Stuart Island tidal front.

where the phase speed is given by

$$
\frac{c}{c_{0}}=\frac{1}{2}+\frac{1}{2} \sqrt{1+\frac{4 u}{c_{0}}} .
$$

The wave energy $E / E_{0}=\left(a / a_{0}\right)^{2}$ is shown in Figure 8 (solid curve) as a function of the normalized current speed $u / c_{0}$. The waves travel from left to right. At $u=0, E / E_{0}=1$ by definition and $E / E_{0}$ goes towards infinity as $u$ goes towards the negative group speed of the wave $\left(u / c_{0}=-1 / 4\right)$.

In reality, waves do not reach infinite amplitudes but break when they reach a certain critical steepness $k a$, given by the product of wave number $k$ and amplitude $a$. This value is given by Longuet-Higgins (1969) as $k a=1 / 2$. Duncan (2001) uses $k a=0.31$ and $\mathrm{Wu}$ and Yao (2004) found values between $k a=0.15$ and $k a=0.36$ if currents are present. We are interested in the amount of gas injected by breaking waves and will use a value of $k a=1 / 2$, which is conservative in the sense that the waves do not break as easily.

The location at which the wave reaches its critical steepness depends on current speed, initial wave number, and wave height. For waves with high initial steepness $k_{0} a_{0}$ this will happen at low current speeds and for waves with lower initial steepness at higher current speeds (Fig. 8). The amplitude at which the wave exceeds the breaking criterion decreases as the wave travels farther against the current, because the wave number increases with current speed. To derive the equation for the energy of a breaking wave, $k a=1 / 2$ is multiplied 


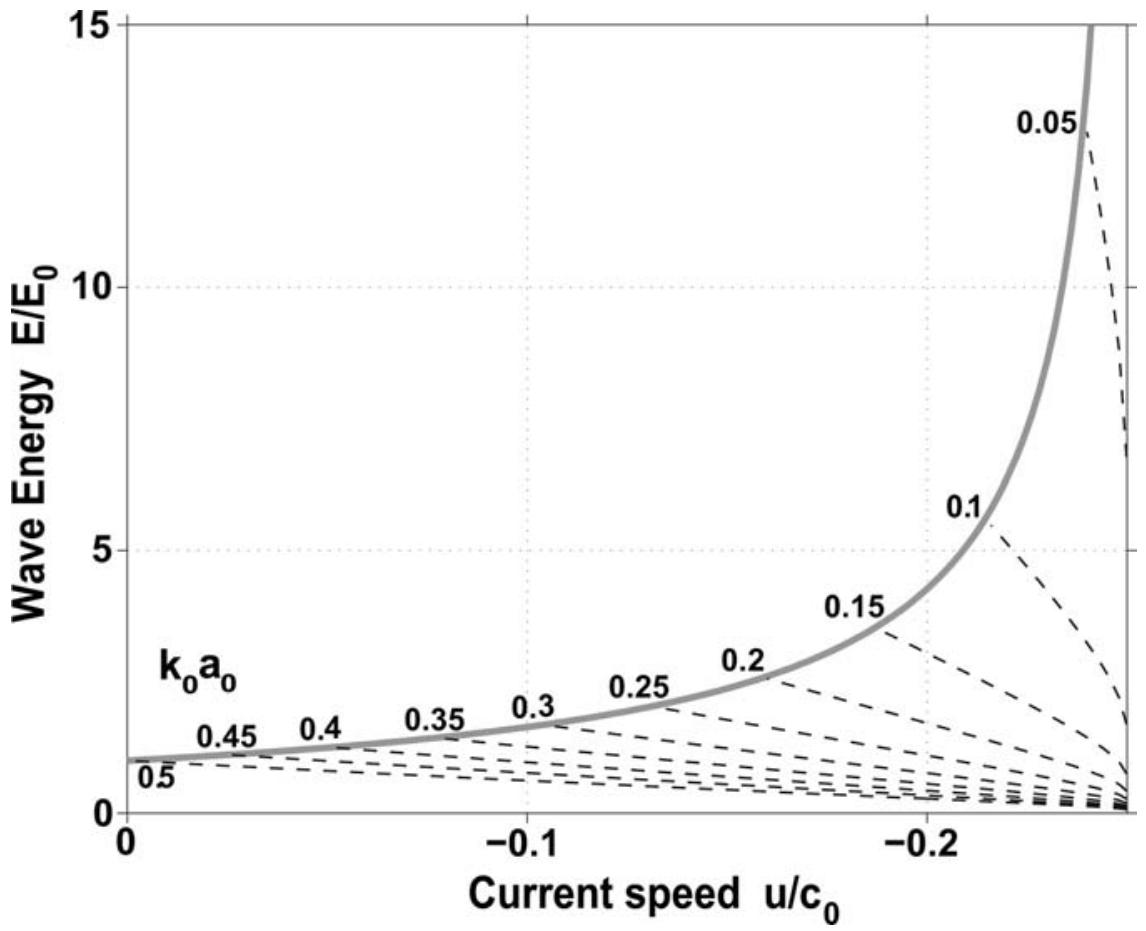

Figure 8. The wave energy without wave breaking (solid curve) and with wave breaking is plotted as function of current speed for a wave of initial steepness $k_{0} a_{0}$ (dashed curves). Current speed and energy are scaled with the values for a medium at rest.

by $1 /\left(k a_{0}\right)$. Together with the expression $\left(c / c_{0}\right)^{2}=k_{0} / k$ we get

$$
\frac{a}{a_{0}}=\left(\frac{c}{c_{0}}\right)^{2} \frac{1}{2 k_{0} a_{0}}
$$

where $c / c_{0}$ is given by Eq. (4). The group velocity equals the current speed when $u / c_{0}=-1 / 4$, i.e. the wave cannot proceed any further against the currents and will have to break somewhere in the convergence zone. $E / E_{0}$ is plotted in Figure 8 for different initial steepnesses $k_{0} a_{0}$ (dashed curves).

\section{a. Wave breaking}

Galvin (1968) has classified different types of breaking waves approaching a sloping bottom. Two of these types, spilling and plunging breakers, can also be found in the open ocean or a convergence zones. Observations show that spilling breakers are predominant in tidal fronts or convergence zones (Fig. 7) and the following considerations will be limited to these waves. 


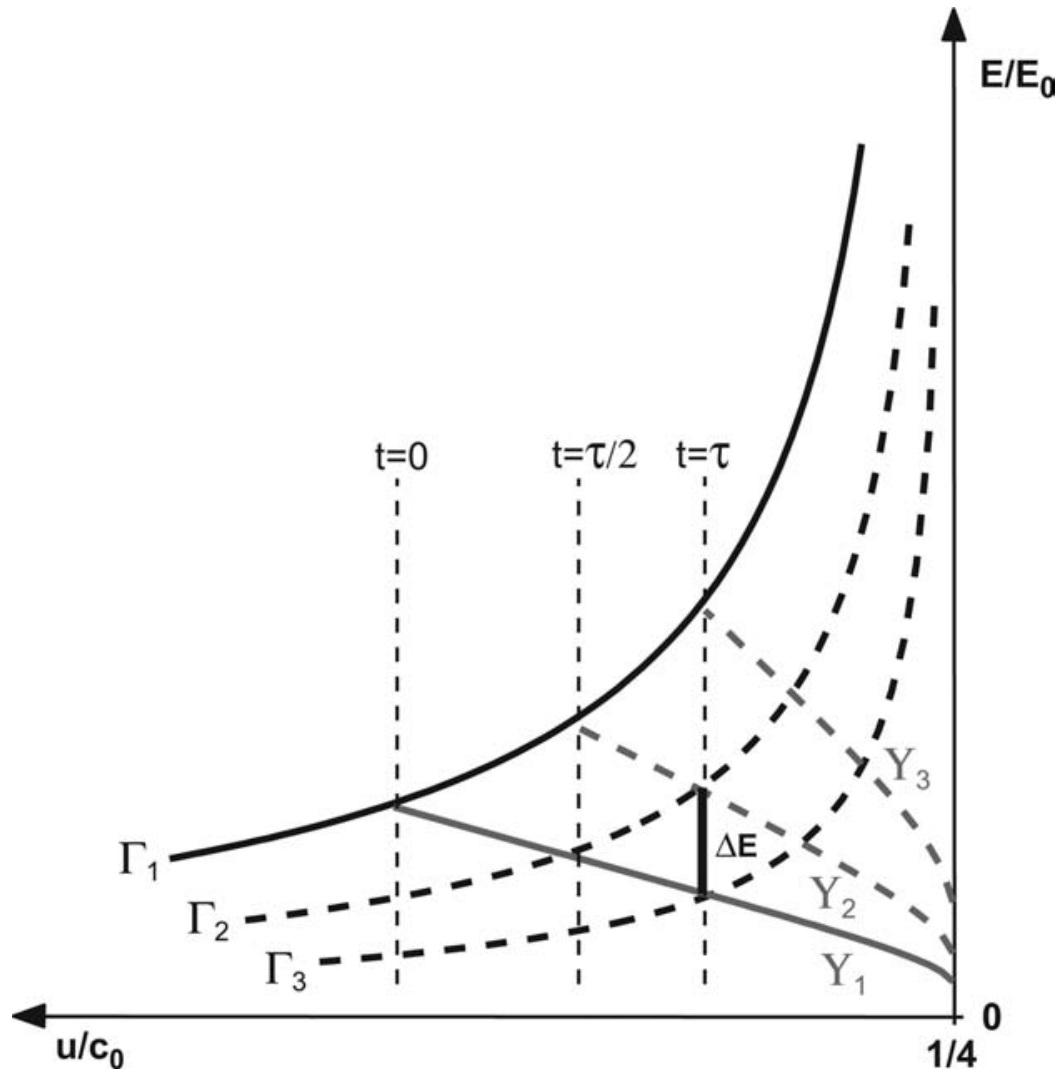

Figure 9. Behavior of a quasi-monochromatic wave on an opposing current. The normalized energy $E / E_{0}$ is given for the case without breaking (black curves $\Gamma_{i}$ ) and with breaking (gray curves $\Upsilon_{j}$ ). $\Delta E$ is the energy lost by wave breaking.

In order to determine the amount and location of injected gas bubbles, the shape of the wave packet has to be considered, as the wave energy is transported with the group speed and not with the phase speed. Consider a wave that is at time $t=0$ at location $x=0$ (on curve $\left.\Gamma_{1}\right)$. The curves $\Gamma_{i}\left(\Gamma_{i} / \Gamma_{1}=\right.$ const., Fig. 9) describe the wave energy without breaking and $\Upsilon_{i}$ the wave energy with breaking. $\Gamma_{1}$ and $\Upsilon_{1}$ mark the shape of the entire wave packet at $t=0$. One period $\tau$ later the wave has moved $\lambda$, and the wave packet $\lambda / 2$, to the right. If there was no wave breaking during this time, the shape of the wave packet would be given by curves $\Gamma_{1}$ and $\Upsilon_{2}$. But because of breaking, the "excess" energy $\Delta E=\Upsilon_{2}(\lambda)-\Upsilon_{1}(\lambda)$ is lost between $x=0$ and $x=\lambda$. From Figure 9 it also follows that $\Upsilon_{2}(\lambda)=\Gamma_{2}(\lambda)$. Putting this together with

$$
\frac{\Gamma_{2}(\lambda)}{\Gamma_{1}(\lambda)}=\frac{\Gamma_{2}(\lambda / 2)}{\Gamma_{1}(\lambda / 2)}=\text { const } . \quad \text { and } \quad \Gamma_{2}(\lambda / 2)=\Upsilon_{1}(\lambda / 2)
$$


yields an equation for the energy loss by wave breaking

$$
\Delta E=\frac{\Upsilon_{1}(\lambda / 2) \Gamma_{1}(\lambda)}{\Gamma_{1}(\lambda / 2)}-\Upsilon_{1}(\lambda)
$$

It should be noted though that due to the effect of the currents the difference in the wave energy between two points of the curve is not equivalent to the dissipated wave energy.

In these idealized conditions, the wave crest is continuously pushed into the region of critical steepness, so that the wave breaks continuously (and not intermittently) in order to satisfy the stability criteria. However, this is not necessarily true if the magnitude of the currents does not increase linearly or if we are looking at the more realistic case of a group of waves rather than a monochromatic wave train. Figure 10 shows a sketch of the breaking behavior of a group of waves on a current. At $t=0$ (a), the first wave has a steepness of $k a>1 / 2$ and breaks. In contrast to open ocean waves (Donelan et al., 1972), the wave packet amplitude is not maintained by a continuous source of wind energy but changes due to breaking and the effects of the currents (b), At $t=\tau$ (c), the first wave has moved $\lambda / 2$

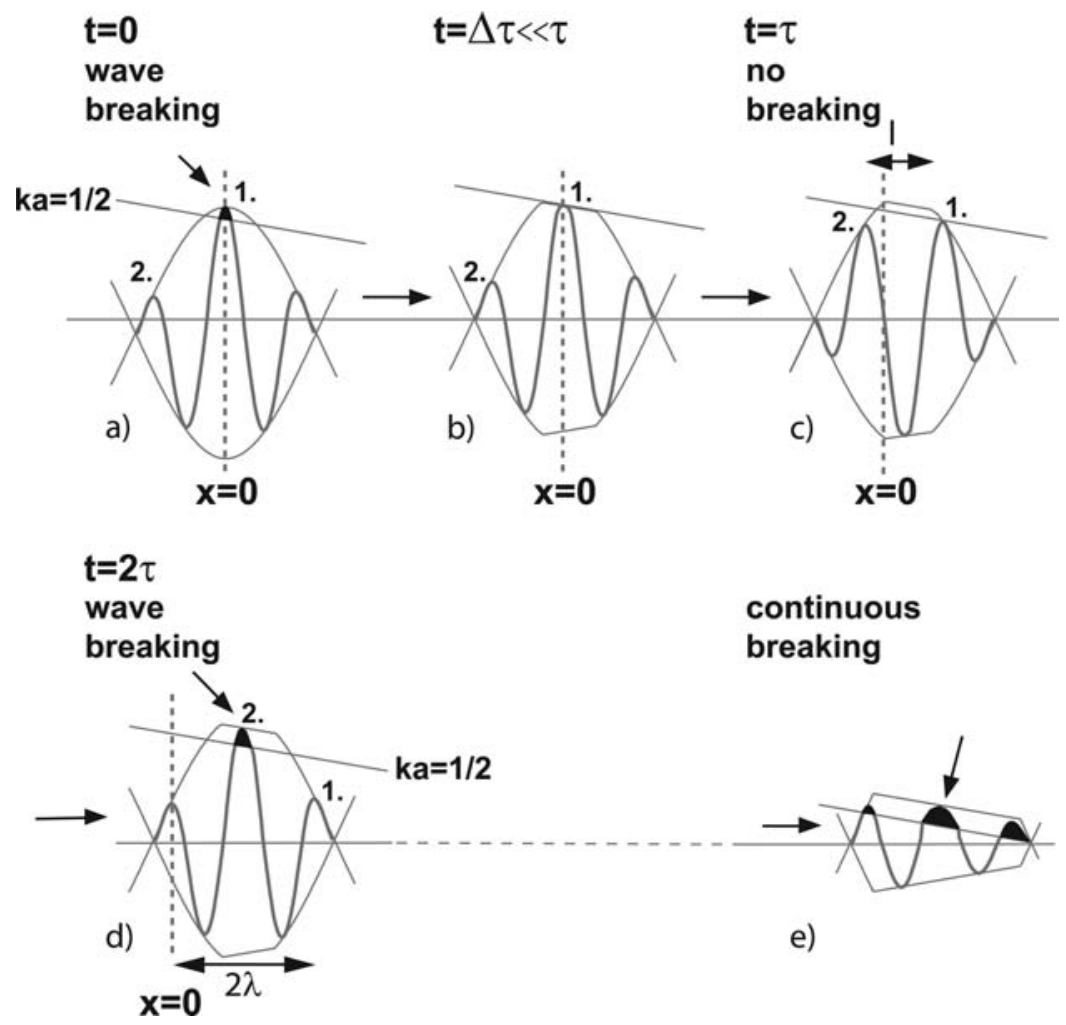

Figure 10. Sketch of the break behavior of a group of waves on a current. For explanations see text. 
to the right (relative to the wave packet) so that its amplitude is reduced. It has a steepness that is less than the critical value and stops breaking. At $t=2 \tau(\mathrm{d})$, the next wave has reached its critical steepness and breaks - with an amplitude that is smaller than the first wave. This intermittent breaking changes at a later stage (e): because the shape of the wave packet is altered by wave breaking and the interaction with the currents, the waves are now continuously pushed into the region of critical steepness and hence break continuously. Depending on the initial shape of the wave packet and the current gradient, there may not be a phase of intermittent breaking. It is also possible that the wave amplitude is reduced more than necessary and the waves break again when they become steep. The energy loss is then step-like instead of continuous. Observations of breaking waves in tidal fronts (Fig. 7) show, however, that almost all waves within the convergence zone are actively breaking whitecaps, indicating that continuous breaking is predominant.

\section{Gas bubble behavior}

Gas bubbles are injected into the ocean by breaking waves and then rise back to the sea surface due to their buoyancy - or may be subducted by downwelling currents. The bubble volume and buoyancy change with hydrostatic pressure and due to the gas exchange with the water. This bubble behavior is described with a one-dimensional model from Thorpe (1982). It provides the temporal change of bubble radius $r$ and molar content $n_{j}$ of a gas $j$ inside the bubble. These are calculated along the path of a bubble so that the model is applicable even in the highly complicated flow field of a tidal front. Bubble-bubble interactions are neglected and it is assumed that the bubbles do not break up any further after they have been injected, so that their size responds only to dissolution and pressure changes.

The gas exchange between bubble and water is driven by the difference of the partial gas pressure in the bubble $P_{j}$ and in the water far from the bubble $P_{w_{j}}$ (Thorpe, 1982, 1984)

$$
\frac{d n_{j}}{d t}=-4 \pi r D_{j} S_{j} N u_{j}\left(P_{j}-P_{w_{j}}\right)
$$

where $P_{j}=\chi_{j}\left(p_{a t m}-g \rho z+2 \gamma r^{-1}\right)$ and $P_{w_{j}}=\left(1+0.01 \sigma_{j}\right) \chi_{j_{a t m}} p_{a t m} . D_{j}, S_{j}, N u_{j}$, and $\sigma_{j}$ are the coefficient of diffusion, the solubility, Nusselt number, and gas oversaturation in water. The time, atmospheric pressure, density of sea water, gravitational acceleration, depth, coefficient of surface tension, and mole fraction are denoted as $t, p_{a t m}, \rho, g, z, \gamma$, and $\chi_{j}$. The gas transfer from the bubble into the water is enhanced by the flow relative to the bubble (rise speed or turbulence). The Nusselt number $N u$ is a dimensionless measure of turbulent gas transfer and is given by the ratio of the total gas exchange and the gas exchange caused by diffusion alone (Woolf and Thorpe, 1991).

The change of bubble radius with time is given by

$$
\frac{d r}{d t}=\left(\frac{3 R T}{4 \pi r^{2}} \sum_{j} \frac{d n_{j}}{d t}-r \frac{d p}{d t}\right)\left(3 p+3 p_{a t m}+\frac{4 \gamma}{r}\right)^{-1}
$$


where the change of the hydrostatic pressure $d p / d t$ is given by the sum of vertical current speed $w$, bubble rise speed $w_{b}$, and turbulent current speed $w_{\text {turb }}$ as

$$
\frac{d p}{d t}=g \rho\left(-w-w_{b}+w_{t u r b}\right)
$$

Gas bubbles rise in a fluid due to their buoyancy. Formulae for their rise speed are given by various authors (e.g. Thorpe, 1982; Woolf and Thorpe, 1991; Keeling, 1993; Fan et al., 1999). Fan and Tsuchiya (1990) merged the results from different studies covering a wide range of radii. We will use their description for bubbles with a layer of surface-active material ("dirty bubbles").

The coupled ordinary differential equations (8), (9), and (10) were solved with an explicit Runge-Kutta formula in MATLAB. For this one-step solver only the solution at the immediately preceding time point is needed, so that the vertical current speed can be described by an arbitrary function of time and also turbulence can be implemented.

The typical scale of the turbulent vertical current speed in a tidal front of $w^{*}=0.05 \mathrm{~m} \mathrm{~s}^{-1}$ has been estimated from observations by Gargett and Moum (1995) in a similar environment in Haro Strait. The vertical displacement of a parcel of water due to the turbulent velocity $w_{\text {turb }}$ (Eq. 10) is calculated by multiplying $w^{*}$ with a random value chosen from a normal distribution with mean zero and standard deviation one. The increased gas flux due to small scale pressure fluctuations is incorporated in the description of the Nusselt Number.

For the model calculations, the gas mixture in the bubbles contains the four gases $\mathrm{O}_{2}, \mathrm{~N}_{2}$, $\mathrm{CO}_{2}$, and Ar. It can be assumed that the injection time of the bubbles is short in comparison to the time scale of diffusion, so that the initial mole fraction in the bubble $\chi_{j}$ at time $t=0$ is equivalent to the atmospheric one. Mole fraction and gas content, however, change after injection due to diffusion. Typical parameter values (Woolf and Thorpe, 1991) used in the model runs are listed in Table 1.

Table 1. Typical values for the parameters used in the model calculations (Woolf and Thorpe, 1991).

\begin{tabular}{lccccc}
\multirow{2}{*}{ Variable } & $\mathrm{O}_{2}$ & $\mathrm{~N}_{2}$ & $\mathrm{CO}_{2}$ & $\mathrm{Ar}$ & Units \\
$n_{j}$ & 1.7 & 1.8 & 1.3 & 1.7 & $10^{-9} \mathrm{~m}^{2} \mathrm{~s}^{-1}$ \\
$\chi_{j}$ & 209.5 & 780.9 & 0.0035 & 9.2 & $10^{-3}$ \\
$S_{j}$ & 13 & 6.29 & 445 & 14.2 & $10^{-6} \mathrm{~mol} \mathrm{~m}^{-1} \mathrm{~Pa}^{-1}$ \\
$\sigma_{j}$ & 0 & 0 & 0 & 0 & $\%$ \\
$T$ & & 283 & & $\mathrm{~K}$ \\
$\rho$ & & 1020 & & $\mathrm{~kg} \mathrm{~m}^{-3}$ \\
$p_{\text {atm }}$ & & $1 \cdot 10^{5}$ & & $\mathrm{~Pa}^{-1}$ \\
$\gamma$ & & 0.036 & & $\mathrm{~m}^{2} \mathrm{~s}^{-1}$ \\
$\nu$ & & $1 \cdot 10^{-6}$ & & $\mathrm{~m} \mathrm{~s}^{-1}$ \\
$w^{*}$ & & 0.05 & &
\end{tabular}




\section{a. Gas entrainment by bubbles}

In the following, we will look at the size distribution of gas bubbles that are injected in the tidal front and will calculate how much of the enclosed air dissolves and contributes to air-sea gas exchange. The air enclosed during wave breaking quickly breaks up into gas bubbles due to pressure fluctuations exerted by turbulence (Deane and Stokes, 1999). These bubbles form a size distribution $N(r)$, that describes the number density in a unit volume of water for each radius increment $r-d r / 2$ to $r+d r / 2$. Numerous measurements (e.g. Johnson and Cooke, 1979; Baldy and Bourguel, 1987; Dean and Stokes, 1999) show that it can be adequately described by power laws of the form $N(r)=\beta r^{\alpha}$, where $\beta$ is a scaling factor that depends on the total number of bubbles. $\alpha$ is the slope of the size distribution (in double-logarithmic space) and has negative values as small bubbles are more numerous than big bubbles.

The values for $\alpha$ given in the literature range between -1.8 and -5.5 . Unfortunately it is difficult to compare these measurements with each other as they were taken in different environments (tank, surf zone, open ocean), different wind and wave conditions (spilling or plunging breakers), measurement depths, or may be influenced by surfactants. In particular the different times relative to initial bubble generation (plume age) are a concern as the bubble size distribution changes due to dissolution, which flattens the spectrum for small bubbles, and due to buoyancy, which steepens the spectrum for larger bubbles (Garrett et al., 2000; Baldy and Bourguel, 1985, 1987; Baldy, 1988; Hwang et al., 1990).

For the modeling of bubble behavior and gas exchange, we are interested in the initial size distribution that is established immediately after bubble formation. Garrett et al. (2000) argue on dimensional grounds that the bubble breakup by turbulence results in an initial size distribution that is proportional to $r^{-10 / 3}$. This was observed by Deane and Stokes (2002) for bubbles with radii $>1000 \mu \mathrm{m}$ generated in the surf zone. For $r<1000 \mu \mathrm{m}$, however, the observed slope was $\alpha=-3 / 2$, which is supported by dimensional considerations for bubble entrainment by a jet of water and implies that most of the small bubbles are formed when the wave curls over and plunges into the sea surface. Although this scenario seems to be more likely for plunging than for spilling breakers and the separation point between the two slopes changes under different conditions, we will use this description with two power laws for the initial bubble size distribution due to the lack of measurements in more relevant conditions.

While it is assumed that the two initial spectral slopes $\alpha$ are constant with depth, the bubble density decreases with depth. Observations indicate that this decay is exponential (e.g. Medwin, 1970; Baldy and Bourguel, 1987; Crawford and Farmer, 1987), so that the size distribution is given by

$$
N(r, z)=\beta_{0} r^{\alpha} e^{z / \delta},
$$

where $\delta$ is the bubble entrainment depth, $\beta_{0}$ the scaling factor at the sea surface, and $z$ the depth (with positive values upwards). The bubble penetration depth increases with the wave amplitude $a$. Chanson and Jaw-Fang (1997) observed $\delta=1.2-2 a$ for a jet or plunging 
breaker generated in a tank and Hwang et al. (1990) found in tank experiments a quasi-linear relationship between significant wave height $H_{s}$ and bubble penetration depth $\left(\delta \approx H_{s}\right)$. Loewen et al. (1996) measured $\delta=0.11-0.34 a$ in a tank, and Thorpe (1986) observed bubbles in the ocean to depths of $2.5-3 H_{s}$ for moderate winds and $4-5 H_{s}$ for strong winds. Also, observations of open ocean whitecaps by Thorpe (1982), Vagle (1989), and Crawford and Farmer (1987) show that the overall number of bubbles and their penetration depth increases with wind speed and hence with wave height. Oceanic measurements, however, may overestimate the initial entrainment depth as bubbles are carried farther down by wave motion or Langmuir circulations. We will use for our calculations a value of $\delta=a / 4$, as it yields the best agreement in void fraction and bubble size distribution with the values for small spilling breakers published by Loewen et al. (1996) (see below).

The total number of injected bubbles depends on the dissipated wave energy $\Delta E$. A part of this energy $E_{b}$ goes into the subduction of newly formed gas bubbles. For a single bubble of radius $r$ it is $E_{b 1}=-4 / 3 \pi r^{3} \rho g z$. The energy that is required to submerge all bubbles of a size distribution $N(r, z)$ is then

$$
E_{b}=-\int_{-\infty}^{0} \int_{r_{1}}^{r_{2}} N(r, z) \frac{4}{3} \pi r^{3} \rho g z d r d z .
$$

If we insert the equation for the size distribution (11), integrate between the cut-off radii $r_{1}$ and $r_{2}$ and over the whole water column, we obtain an equation for the scaling factor $\beta_{0}$ that describes the total number of gas bubbles at the sea surface

$$
\begin{array}{rlrl}
\beta_{0}(x) & =\frac{3(\alpha+4) \mathcal{E} \Delta E}{4 \pi g \rho \delta^{2}}\left(r_{2}^{\alpha+4}-r_{1}^{\alpha+4}\right)^{-1} & & \text { for } \\
& =\frac{3 \mathcal{E} \Delta E}{4 \pi \rho g \ln \left(r_{2} / r_{1}\right)} & \text { for } \quad \alpha=-4,
\end{array}
$$

where $\mathcal{E} \equiv E_{b} / \Delta E$ is defined as the ratio of energy required for the subduction of bubbles to the total dissipated wave energy. Due to the current speed gradients, $\Delta E, \delta$, and $\beta$ are functions of horizontal distance $x$. The water density is $\rho=1023.5 \mathrm{~kg} \mathrm{~m}^{-3}$.

If a part of the bubble spectrum is not detected, $\beta_{0}$ is underestimated. For $\alpha>-4$, the void fraction is mainly determined by large bubbles and for slopes of $\alpha<-4$ it is determined by small bubbles. For our bubble spectrum, this means that the cut-off radius for small bubbles $r_{1}$ is not critical as the spectral slope is $\alpha=-3 / 2>-4$. The cut-off radius for large bubbles $r_{2}$, however, is important for calculating gas entrained by bubbles as $\alpha=-10 / 3>-4$. Hence, the void fraction is dominated by the larger bubbles. For our model calculations we will use $r_{1}=20 \mu \mathrm{m}$ and $r_{2}=10000 \mu \mathrm{m}$, covering the whole measurement range.

Measurements of breaking waves show that between $10 \%$ and $60 \%$ of the wave energy is dissipated during breaking (e.g. Chanson and Jaw-Fang, 1997; Melville and Rapp, 1985; Nepf et al., 1998). The portion of this energy that goes into the subduction of gas bubbles is $\mathcal{E}=1.5-4.2 \cdot 10^{-3}$ for small spilling breakers (Loewen et al., 1996) or as high as $\mathcal{E}=$ 

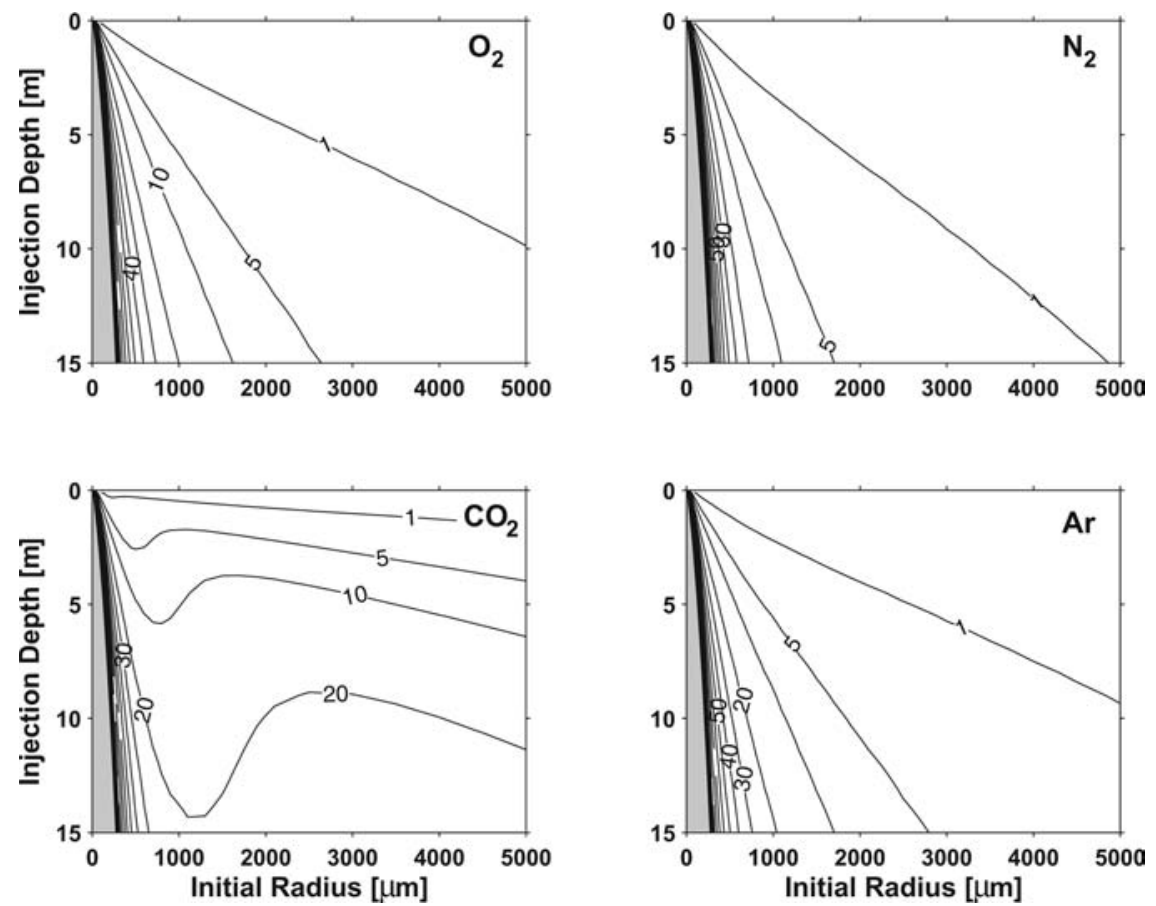

Figure 11. Percentage of gas $d(r, z)$ that dissolves from a bubble while it rises back to the surface. It is shown for $\mathrm{O}_{2}, \mathrm{~N}_{2}, \mathrm{CO}_{2}$, and $\mathrm{Ar}$ as a function of initial bubble radius and depth. The gray shaded area marks the bubbles that dissolve completely.

0.3-0.5 for small plunging breakers (Lamarre and Melville, 1991). The appropriate value for a breaking wave on a current is therefore quite uncertain and varies over two orders of magnitude. It is likely that it depends on the current speed gradient a wave experiences: a sudden current change may result in a plunging breaker, while a gradual change may result in a spilling breaker. We chose a conservative value of $3 \cdot 10^{-3}$, as for a small spilling breaker with an amplitude of only a few centimeters.

While Eq. (13) yields the total number of gas bubbles entrained, we are especially interested in the amount of gas that actually dissolves from the bubbles. The amount of gas $d(r, z)$ a single bubble loses to the surrounding water before it rises back to the sea surface depends on the initial bubble radius, the injection depth, and the vertical current. It has been calculated with the bubble model and is plotted in Figure 11 for a range of radii and injection depths for $\mathrm{N}_{2}, \mathrm{O}_{2}, \mathrm{CO}_{2}$, and $\mathrm{Ar}$ and no vertical currents. The gas saturation is $100 \%$ for all gases. The smaller bubbles dissolve completely (marked by the gray shaded area) while the larger ones rise to the surface where the remaining gas is released.

Downwelling currents keep the injected bubbles underwater for longer, increasing the time during which gas dissolves. This is obvious in Figure 12 where $d(r, z)$ is plotted for a uniform vertical current speed of $w=-0.2 \mathrm{~m} \mathrm{~s}^{-1}$ (right at the surface $w=0$ ). A bubble 

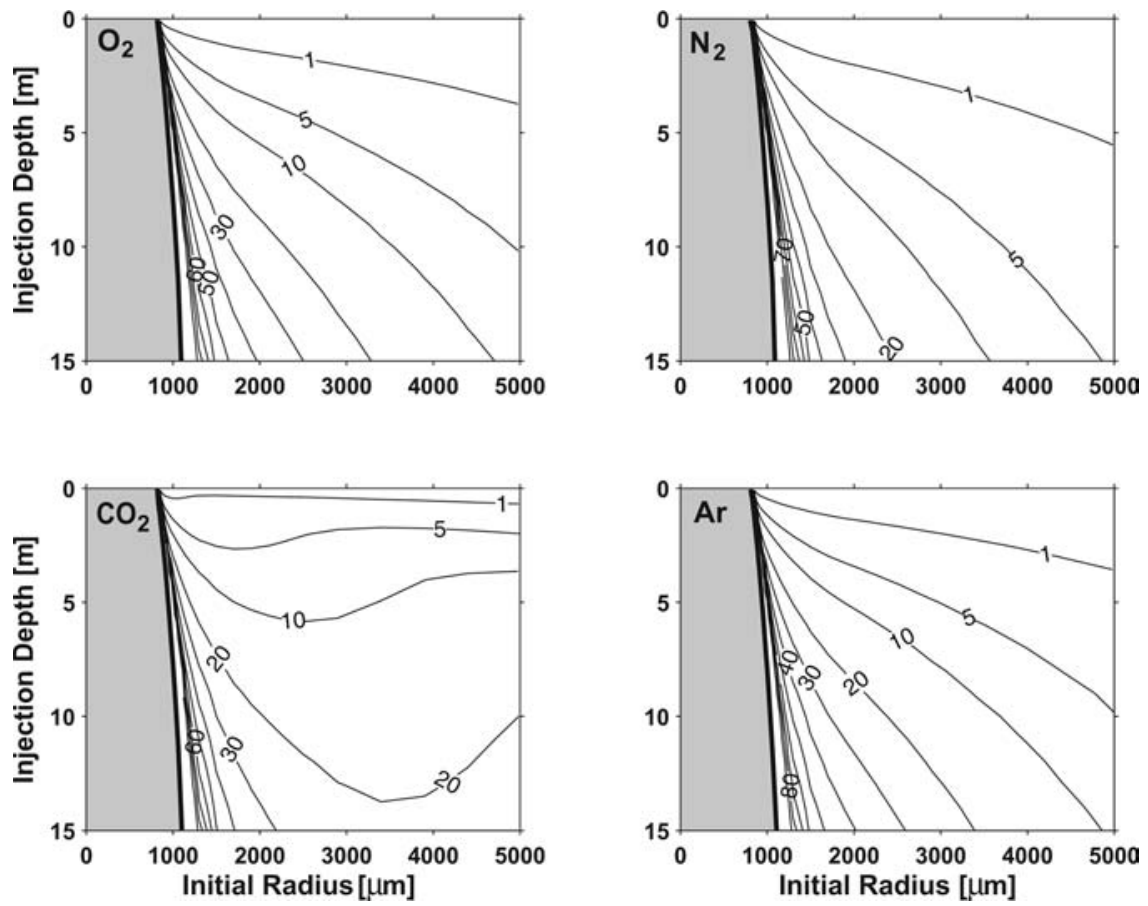

Figure 12. Percentage of gas $d(r, z)$ that dissolves from a bubble while it rises back to the surface. It is shown for $\mathrm{O}_{2}, \mathrm{~N}_{2}, \mathrm{CO}_{2}$, and $\mathrm{Ar}$ as a function of initial bubble radius and depth and for a current speed of $w=-0.2 \mathrm{~m} \mathrm{~s}^{-1}$.

dissolves completely if the vertical currents are stronger than its (initial) rise speed. The larger bubbles lose more gas than without currents, but still reach the sea surface.

The total percentage of gas dissolved $G_{j}$ is given by the integral over all bubbles of a given size and depth distribution

$$
G_{j}=\frac{\int_{r_{1}}^{r_{2}} \int_{-\infty}^{0} d_{j}(r, z) N(r, z) V_{0}(r, z) d z d r}{\int_{r_{1}}^{r_{2}} \int_{-\infty}^{0} N(r, z) V_{0}(r, z) d z d r},
$$

where the initial volume of a bubble, which it would have at the sea surface under only atmospheric pressure $p_{\text {atm }}$, is given by

$$
V_{0}=\frac{4}{3} \pi r^{3}\left(\frac{-g \rho z}{p_{a t m}}+1\right) .
$$

$G_{j}$ has been plotted in Figure 13 as a function of the vertical current for bubble radii between $1 \mu \mathrm{m}$ and $10,000 \mu \mathrm{m}$ and $\delta=0.1 \mathrm{~m}$. It increases slowly for currents up to $-0.2 \mathrm{~m} \mathrm{~s}^{-1}$ and much more rapidly between $-0.2 \mathrm{~m} \mathrm{~s}^{-1}$ and $-0.3 \mathrm{~m} \mathrm{~s}^{-1}$. This sudden increase can be explained by the function describing the rise speed of gas bubbles (Fan and 


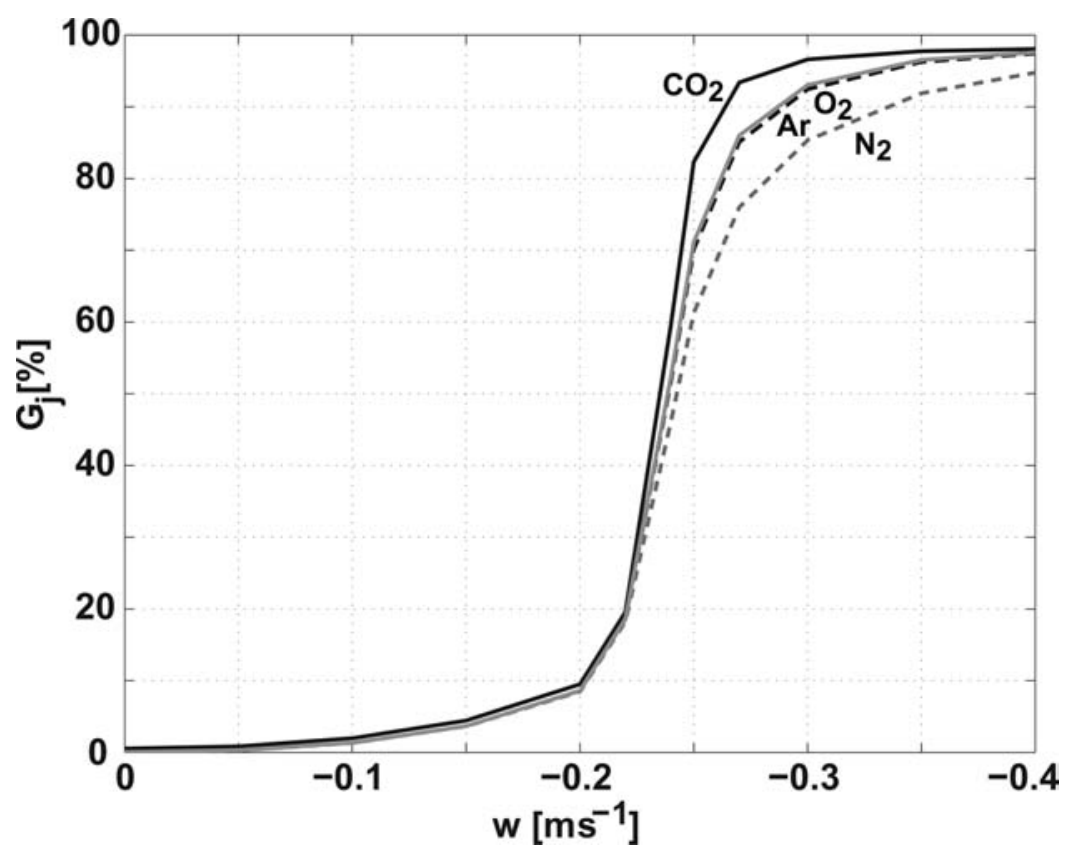

Figure 13. Percentage of the total amount of gas dissolved $G_{j}$ as function of current speed $w$ for an entrainment depth of $\delta=0.1 \mathrm{~m}$.

Tsuchiya, 1990). For radii between $700 \mu \mathrm{m}$ and $7000 \mu \mathrm{m}$, the bubble rise speed increases only gradually from $0.2 \mathrm{~m} \mathrm{~s}^{-1}$ to $0.3 \mathrm{~m} \mathrm{~s}^{-1}$. Therefore, only a slight increase in current speed greatly enhances the number of bubbles that are drawn down and dissolve. $G_{j}$ also depends on the assumed entrainment depth $\delta$, because bubbles that are injected deeper have a longer path through the water column. For example, for $\delta=1 \mathrm{~m}, G_{j}$ increases for all gases by a factor of $2-4$ for $w<0.22 \mathrm{~m} \mathrm{~s}^{-1}$.

The differences in the curves for the four gases are caused by the different diffusion speeds which are proportional to $S D^{2 / 3}$, where $S$ is the solubility and $D$ the coefficient of diffusion. $\mathrm{CO}_{2}$ dissolves more quickly than the other gases, and for currents stronger than $-0.25 \mathrm{~m} \mathrm{~s}^{-1}$ all $\mathrm{CO}_{2}$ is lost. $\mathrm{N}_{2}$ has a low diffusion rate, so that "old" bubbles contain mostly $\mathrm{N}_{2}$.

\section{b. Application to the sill flow at Boundary Pass}

The amount of gas dissolved in a tidal front depends on the injection location relative to the plunge point of the subducting water mass: the closer to the plunge point the bubbles are injected, the less time the bubbles have to rise back to the surface before they are subducted, and the more gas dissolves. The considerations in the previous section can be directly applied to this situation: in a reference frame moving with the currents, the bubbles experience a temporally varying vertical velocity. 
Table 2. For an estimate of the air-sea gas exchange at Boundary Pass, three representative waves with different amplitudes and wave lengths were chosen approaching the front from East and West.

$\longleftarrow$ Waves from the East

$\begin{array}{ccccc}\text { Wave } & a_{0}[\mathrm{~m}] & \lambda_{0}[\mathrm{~m}] & a_{0} k_{0} & \text { Break Region } \\ \text { I } & 0.05 & 1.5 & 0.32 & 74 \mathrm{~m} \text { to } 42 \mathrm{~m} \\ \text { II } & 0.2 & 8 & 0.13 & 7 \mathrm{~m} \text { to }-17 \mathrm{~m} \\ \text { III } & 1 & 15 & 0.42 & 85 \mathrm{~m} \text { to }-47 \mathrm{~m}\end{array}$

$\longrightarrow$ Waves from the West

$\begin{array}{ccccc}\text { Wave } & a_{0}[\mathrm{~m}] & \lambda_{0}[\mathrm{~m}] & a_{0} k_{0} & \text { Break Region } \\ \text { I } & 0.05 & 1.5 & 0.32 & -13 \mathrm{~m} \text { to } 1 \mathrm{~m} \\ \text { II } & 0.2 & 8 & 0.13 & 33 \mathrm{~m} \text { to } 84 \mathrm{~m} \\ \text { III } & 1 & 15 & 0.42 & >16 \mathrm{~m}\end{array}$

Waves that approach the tidal front at Boundary Pass encounter two slightly different situations: waves approaching from the west ride on the strong flood tidal currents until they reach the front marking the transition to the stagnant surface layer in the east. For waves approaching from the east, the transition is from stagnant water to fast opposing currents. The model of wave-current interaction is used to calculate the location of bubble injection and the dissipated wave energy. This yields the amount of injected and dissolved air as a function of horizontal distance. A sensitivity study is used to estimate the error of the model calculations due to the uncertainties in the parameters (Appendix).

In the following, three different waves are chosen as examples. They may represent wind/wave conditions on a calm, average, and windy day. The wind speeds in the Strait of Georgia are usually less than $15 \mathrm{~m} \mathrm{~s}^{-1}$, with prevailing winds of less than $7 \mathrm{~m} \mathrm{~s}^{-1}$. The conditions are usually fetch-limited and the expected wave height is up to $1.5 \mathrm{~m}$, but usually less than $0.6 \mathrm{~m}$ (Bretschneider, 1958). In particular, the following values for the initial amplitude $a_{0}$ and wave length $\lambda_{0}$ are chosen: $a_{0}=0.05 \mathrm{~m}, \lambda_{0}=1.5 \mathrm{~m}$ (wave I, calm day; Table 2), $a_{0}=0.2 \mathrm{~m}, \lambda_{0}=8 \mathrm{~m}$ (wave II, average day), and $a_{0}=1 \mathrm{~m}, \lambda_{0}=15 \mathrm{~m}$ (wave III, windy day). The initial steepness of all waves is below the critical value for breaking. The horizontal surface currents are taken from ship-board observations in the tidal front (Fig. 5).

The results are plotted in Figures 14 and 15. The initial wave length $\lambda_{0}$ determines the phase speed of the wave and hence how far the wave proceeds against the current before it reaches the critical value of $u / c_{0}=-1 / 4$ where it is arrested. Long waves advance farther against the current (Fig. 14b and 15a) and waves with a high initial steepness break earlier than waves that are not so steep (Fig. 8). Hence, the initial steepness determines the beginning, and the wave length the end, of the break region.

The horizontal currents carry the bubbles into regions of different $w$, so that for each injection location, the vertical currents are described as a function of time (in a reference frame moving horizontally with the currents/bubbles). It is assumed that $w=0$ to the east of the front, and that the bubbles that are injected at a location to the west of the front are carried downward by the vertically averaged lower layer currents as soon as they are advected 

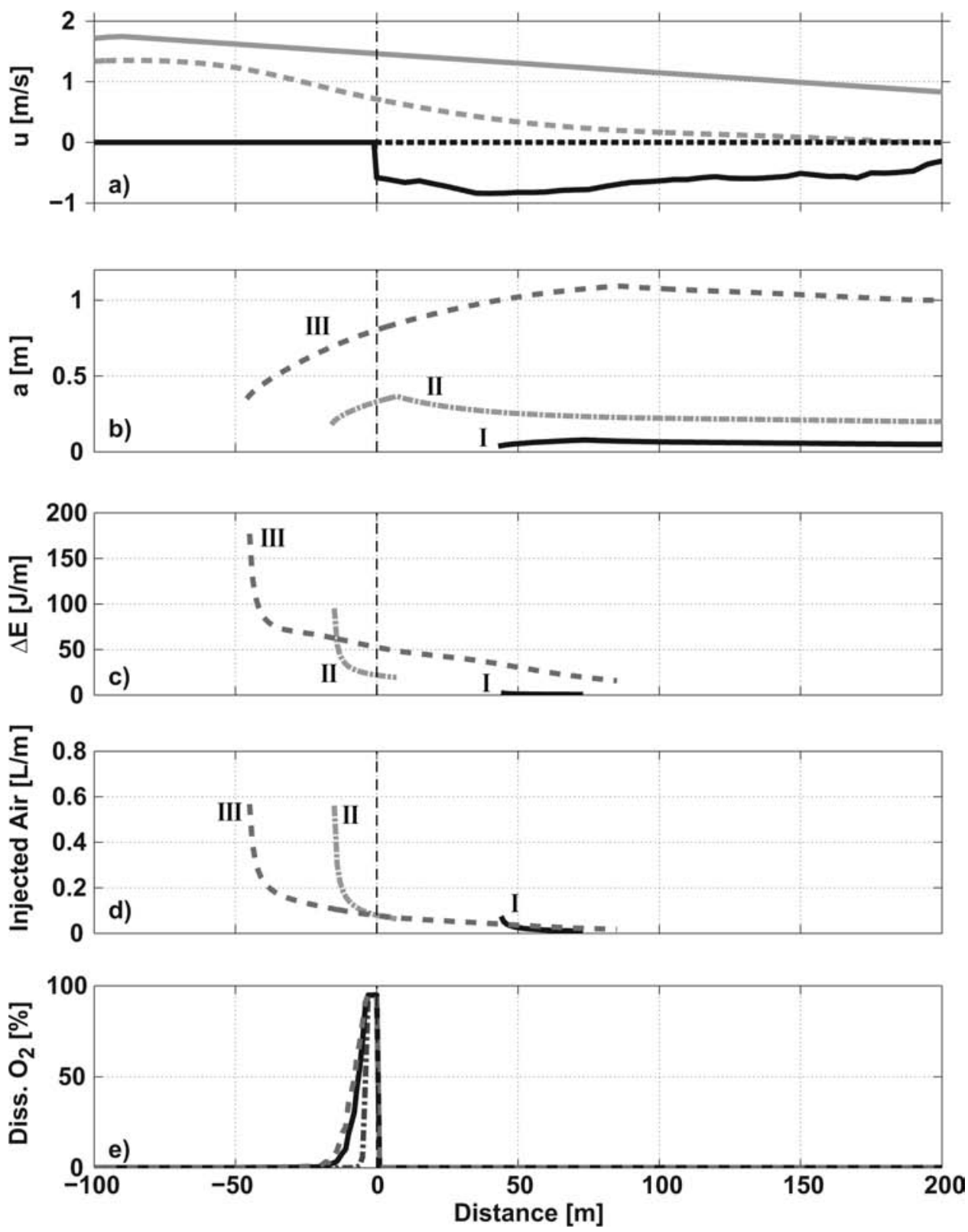

Figure 14. (a) Horizontal (gray) and vertical (black) current in the tidal front at Boundary Pass. Surface currents are shown by dashed lines, vertically averaged lower layer currents by solid lines. (b)-(c) Amplitude and dissipated energy for waves I, II, and III approaching the front from the East; (d) amount of air injected; (e) percentage of oxygen dissolved for detrainment depths $0.05 \mathrm{~m}$ (dashed), $0.5 \mathrm{~m}$ (solid black), and $1 \mathrm{~m}$ (dash-dotted). 

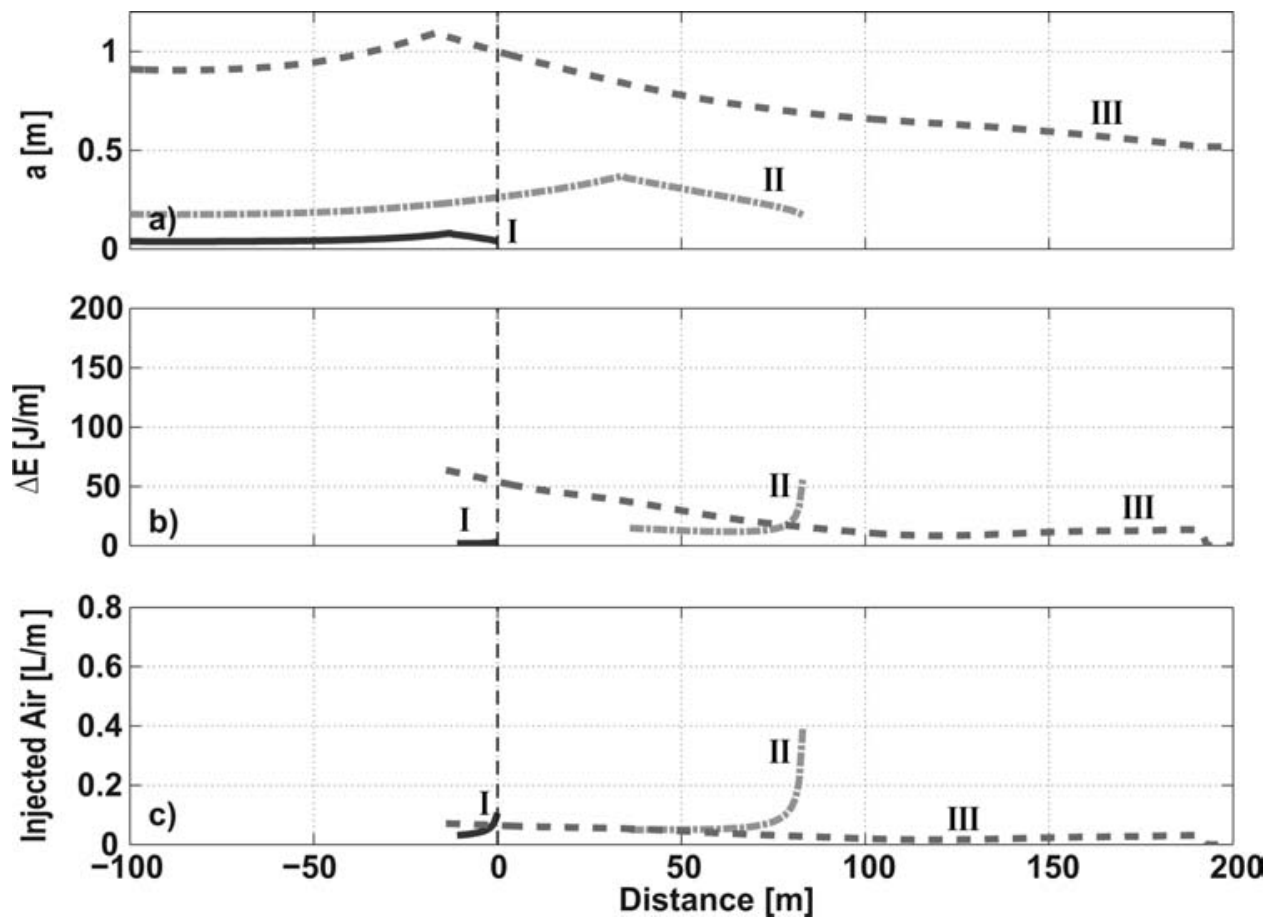

Figure 15. (a)-(b) Amplitude and dissipated energy for waves I, II, and III approaching the front from the West; (c) amount of air injected.

horizontally past the plunge point. The initial size distribution of the injected bubbles is calculated as a function of horizontal distance and depth (13). The resulting vertically integrated void fraction is shown for $\mathrm{O}_{2}$ in Figures $14 \mathrm{~d}$ and $15 \mathrm{c}$ for the entrainment depths $0.05 \mathrm{~m}, 0.5 \mathrm{~m}$, and $1 \mathrm{~m}$.

Bubbles injected within 3-5 $\mathrm{m}$ to the west of the tidal front dissolve almost completely due to the very strong vertical currents exceeding the rise speed of even the largest bubbles. In this zone, the total amount of gas dissolved does therefore not depend on $\delta$. Farther to the west, $G_{j}$ decreases as some of the bubbles have time to rise back to the sea surface. Between $x=-3 \mathrm{~m}$ and $x=-17 \mathrm{~m}, G_{j}$ drops from $95 \%$ to less than $3 \%$ for all three entrainment depths. To the east of the front, the surface layer is stagnant and $G_{j}$ is $<3 \%$.

For an estimate of the frontal contribution to the aeration of the subsurface water in the Strait of Georgia, we are only interested in the dissolved gas that is subducted by the currents (Fig. 14 and 15). The gas that is injected to the east of the front stays in the surface layer and can be neglected, although the gas exchange in that region is also increased by enhanced wave breaking in the vicinity of the front. The waves that contribute most to the aeration of the intermediate water are those that break within the zone of high dissolution close to the front. For waves approaching from the West, this is the case for short initial wave lengths 


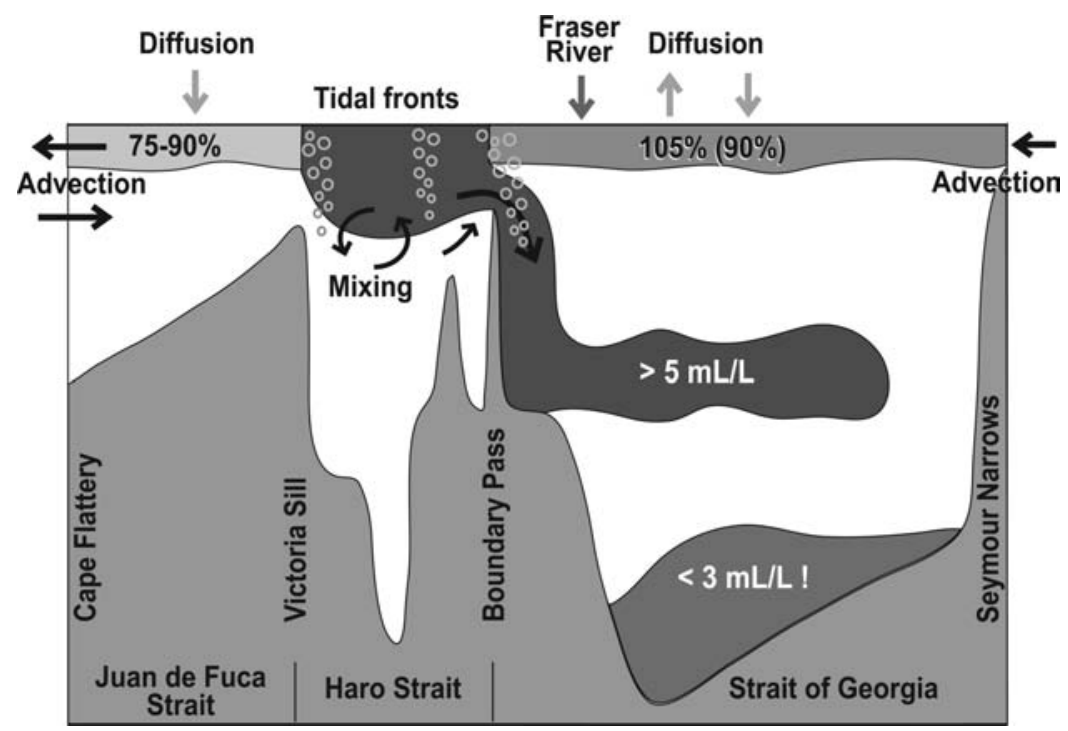

Figure 16. Sketch of the oxygen sources and sinks in the Fraser Estuary. The numbers show the dissolved oxygen saturations in the surface water [\%] and the oxygen concentrations in the subsurface water $\left[\mathrm{mL} \mathrm{L}^{-1}\right]$.

(wave I). Waves approaching from the East can only contribute if they have a wave length of more than $5 \mathrm{~m}$ (waves II, III), so that they are fast enough to travel past the front.

\section{Oxygen Budget of the Fraser Estuary}

In order to determine the contribution of tidal fronts to air-sea gas exchange, a comparison must be made with other oxygen sinks and sources: diffusion through the sea surface, bubble injection by breaking wind waves, advection by currents, as well as biological production and consumption (Fig. 16). For the entire Fraser Estuary, including the surface waters, the contribution of tidal fronts is $<1 \%$ (Baschek, 2003). Here, we focus on the oxygen budget of the subsurface waters in the Strait of Georgia. The surface waters of Juan de Fuca Strait and the Strait of Georgia do not contribute directly to this. The tongue of oxygenated water that subducts to intermediate depths in the Strait of Georgia (Fig. 2) has its origin in Haro Strait, where tidal fronts contribute to the aeration, and oxygen rich surface water is mixed with dense water from the Pacific Ocean.

\section{a. Contribution of tidal fronts}

The tidal front at Boundary Pass is the most pronounced front in Haro Strait. The oxygen flux in this front will be estimated from the model results as well as from measurements of bubble size distribution and current speed. Extrapolation to other fronts in the Strait leads to an estimate of the total gas flux. A minimal value will be given as well as a "best 
guess". Notwithstanding the uncertainties, our use of conservative estimates throughout should provide a lower bound to the flux.

$i$. Estimate from model results. The oxygen flux in the tidal front at Boundary Pass has been estimated for strong flood tidal forcing by applying models of wave-current interaction and bubble behavior in the front. This yields the amount of gas injected by each breaking wave, which is then multiplied by the mole fraction of oxygen $(0.21)$ and the width of the front $(2200 \mathrm{~m})$ and is divided by the wave period. It is assumed that these processes take place twice a day for a $2 \mathrm{~h}$ period during flood tide and the results are averaged over $1 \mathrm{~d}$.

Only the bubbles injected by waves breaking within a few meters of the front contribute to the aeration of intermediate water in the Strait of Georgia. The oxygen flux for waves reaching this zone is $\sim 0.02 \mathrm{~m}^{3} \mathrm{~s}^{-1}$. We emphasize that this is a minimal value given the selection of the values for gas saturation, entrainment depth $\delta$, and the portion of energy $\mathcal{E}$ that goes into bubble subduction. The estimate does not change much, if a different gas saturation level or a different spectral shape are chosen. It is, however, quite sensitive to $\mathcal{E}$ and $\delta$ (Appendix). The values in the reference model runs are given for small spilling breakers with amplitudes of only a few centimeters. For only slightly higher waves, $\delta$ may increase by a factor of $4, \mathcal{E}$ by a factor of up to 100 (for small plunging breakers). We use intermediate values of $\delta=a / 2$ and $\mathcal{E}=0.03$ as a best, yet conservative, estimate of actual conditions with a resulting gas flux of $0.1 \mathrm{~m}^{3} \mathrm{~s}^{-1}$.

ii. Estimate from observations. Direct measurements of gas bubbles provide an alternative way of estimating the gas flux in a tidal front. The void fraction $\mathcal{V}$ is multiplied by the mole fraction of oxygen $\chi$, the bubble entrainment depth $\delta$, the current speed $u$ with which the bubbles are carried past the plunge point, the width $\mathcal{W}$ and length $\mathcal{L}$ of the front, as well as the duration of gas entrainment $\mathcal{T}$ (in $\mathrm{h}$ ) during a $12 \mathrm{~h}$ tidal period. This yields the gas flux in the entire front averaged over a tidal period

$$
\text { Gas flux }=\mathcal{V} \chi\left(\mathrm{O}_{2}\right) \delta u \mathcal{W} \mathcal{L} \mathcal{T} / 12
$$

An Acoustical Resonator for measuring bubble size distributions was towed through the tidal front at Boundary Pass. The void fraction in the bubble plume at a depth of $20 \mathrm{~m}$ is $\mathcal{V}=9.9 \cdot 10^{-7}$ (Fig. 17). The initial bubble size distribution is derived from this for different current speeds by using the bubble model to track the bubbles back to the surface. The resulting void fraction at the surface varies within a factor of 2 , with a mean value of $1.1 \cdot 10^{-5}$.

Echo sounder measurements taken at the same time suggest, however, that bubbles outside the measurement range may have been present (Fig. 6). The gas bubbles at 100 m must have had a radius of at least $0.9 \mathrm{~mm}$ at the surface, which is larger than the largest bubble detected by the Resonator. Smaller gas bubbles may also have been present, but were not measured and may have dissolved completely before reaching the measurement depth. To estimate the amount of gas contained in bubbles outside the measurement range, the bubble size distribution is extended to smaller bubbles with a spectral slope of $-3 / 2$, as used in the 

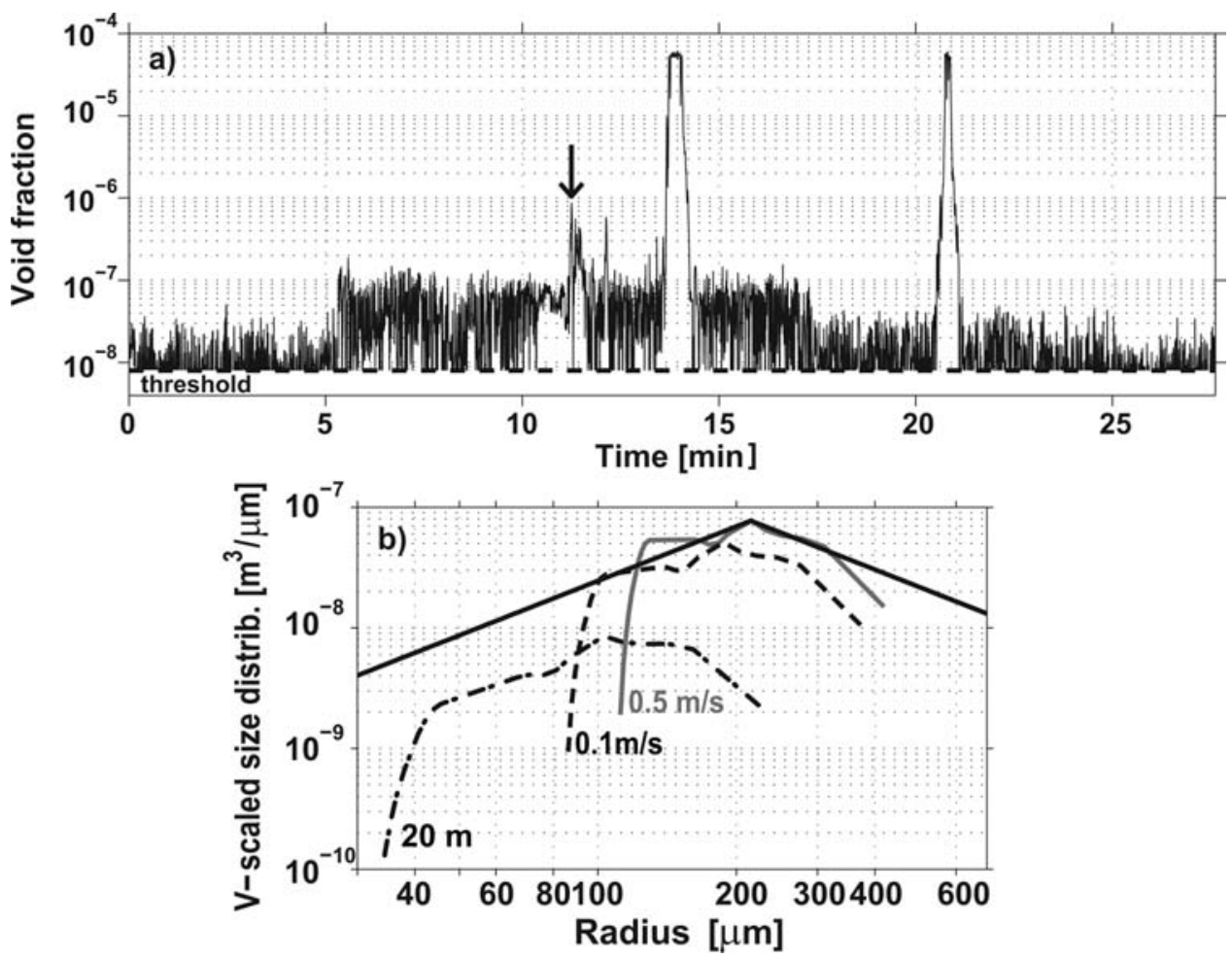

Figure 17. (a) Void fraction during the transect shown in Figure 6. (b) Volume scaled bubble size distribution $4 / 3 \pi r^{3} N(r)$ (dash-dotted curve) of the bubble plume in the front in $20 \mathrm{~m}$ depth (marked by arrow in upper panel and by the black dot in Figure 11). The bubble size distribution at the surface is calculated with the bubble model for $w=0.1 \mathrm{~m} \mathrm{~s}^{-1}$ and $w=0.5 \mathrm{~m} \mathrm{~s}^{-1}$.

previous model calculations. For larger bubbles, we use $\alpha=-4.8$ matching the slope of the observed surface spectra (Fig. 17b). The resulting void fraction of the total spectrum is $2.3 \cdot 10^{-5}$, which is equivalent to an increase in dissolved oxygen by $4.6 \cdot 10^{-3} \mathrm{~mL} \mathrm{~L}^{-1}$.

Even this value for the void fraction is, however, two orders of magnitude smaller than the observations under small spilling breakers by Loewen et al. (1996) and 4 orders of magnitude smaller than the observations under bigger waves (Deane, 1997; Lamarre and Melville, 1991; Loewen et al., 1996; Monahan, 1993). This is not that surprising, given the great natural variability in a turbulent front. We therefore chose a value derived from our observations as a minimal value and the measured void fraction for small spilling breakers of 0.002 (Loewen et al., 1996) as a best guess, assuming that they are injected in the upper $0.15 \mathrm{~m}$ of the water column $(0.05 \mathrm{~m}$ as minimal value).

The speed with which the bubbles are advected past the lower layer plunge point is $1.5 \mathrm{~m} \mathrm{~s}^{-1}$ in the horizontal and somewhere between $-0.2 \mathrm{~m} \mathrm{~s}^{-1}$ and $-0.7 \mathrm{~m} \mathrm{~s}^{-1}$ in the vertical. We take a minimal vertical current speed of $-0.2 \mathrm{~m} \mathrm{~s}^{-1}$ and an average value of 
$-0.5 \mathrm{~m} \mathrm{~s}^{-1}$ as a best guess, so that the resulting current speeds are $1.5 \mathrm{~m} \mathrm{~s}^{-1}$ and $1.6 \mathrm{~m} \mathrm{~s}^{-1}$, respectively. The width of the front $\mathcal{W}$ is given by the zone in which the injected gas bubbles are subducted by the currents before they rise back to the sea surface. This value is between $5 \mathrm{~m}$ and $17 \mathrm{~m}$, with a best guess of $10 \mathrm{~m}$. The length of the front $\mathcal{L}=2200 \mathrm{~m}$ is given by the geometry of the sill. The resulting minimal average gas flux is $6.6 \cdot 10^{-4} \mathrm{~m}^{3} \mathrm{~s}^{-1}$ and for the best guess $0.37 \mathrm{~m}^{3} \mathrm{~s}^{-1}$. Notwithstanding the uncertainties in the measurements and in the seasonal and neap tidal variability, these calculations provide a framework for estimating the role of tidal fronts in air-sea gas exchange.

iii. Contribution of all tidal fronts in Haro Strait. The results from the tidal front at Boundary Pass can now be used to estimate the contribution of the other tidal fronts in Haro Strait. A parcel of water moving from Juan de Fuca Strait into the Strait of Georgia will pass several of these fronts - due to the changing flow direction of the tidal currents possibly even more than once. About $9 \mathrm{ebb}$ and 7 flood tidal fronts are located in the estuary (Fig. 3). Aerial photos and GPS measurements were used to map the extent of these fronts. Ignoring the weaker fronts and including only the ebb tidal fronts at Stuart Island (0.5), Battleship Island (0.3), Gooch Island (0.2), and Discovery Island (0.2), as well as the flood tidal fronts at Boundary Pass (1) and Stuart Island (0.2), where values in parentheses provide an approximate estimate of their relative contribution to aeration. The oxygen flux in all fronts in Haro Strait is therefore about 2.5 times that of Boundary Pass, yielding an oxygen flux for the intermediate water in the Strait of Georgia of $0.92 \mathrm{~m}^{3} \mathrm{~s}^{-1}$ (best guess) and $6.6 \cdot 10^{-4} \mathrm{~m}^{3} \mathrm{~s}^{-1}$ (minimal value).

\section{b. Comparison with other oxygen sources}

In the following, the gas exchange in tidal fronts is compared with the diffusive gas flux and biological production. Due to the strong tidal currents and mixing in Haro Strait and the sparsity of data, it is not possible to estimate reliably the contribution of advection or biological decomposition. For further discussion see Baschek (2003).

The diffusive gas flux was estimated from oxygen data (Crean and Ages, 1971) and hourly wind speed measurements from 1998 at Sandhead, Strait of Georgia. The data may not be representative for the whole estuary, and wind and saturation data are taken from different (possibly untypical) years and at only a few stations. Nevertheless, these numbers provide an estimate of the order of magnitude of the diffusive gas flux. The parameterizations by Wanninkhof (1992) and Liss and Merlivat (1986) yield an annual mean oxygen flux for Haro Strait of $7.6 \mathrm{~m}^{3} \mathrm{~s}^{-1}$ and $4.5 \mathrm{~m}^{3} \mathrm{~s}^{-1}$. The oxygen production by algae has been estimated from a daily primary production rate of $520 \mathrm{mgC} \mathrm{m}^{-2} \mathrm{~d}^{-1}$ (Koblents-Mishke, 1965), which results in a mean oxygen production rate of $5 \mathrm{~m}^{3} \mathrm{~s}^{-1}$ for Haro Strait (Kirke, 1994).

The oxygen budget can now be calculated for the intermediate water in the Strait of Georgia. Diffusion and photosynthesis contribute about the same amount to the additional production of oxygen in the subducting layer (Table 3 ). The tidal fronts contribute about $8 \%$ to the aeration of intermediate water (best guess), or $14.2 \%$ of the diffusive gas flux. The tidal front at Boundary Pass by itself contributes $3 \%$. 
Table 3. Oxygen sinks and sources $\left[\mathrm{m}^{3} \mathrm{~s}^{-1}\right]$ of the Strait of Georgia and the Fraser Estuary. The values for the tidal front are the ones for the "best guess". *) Taken from Thomson (1994). **) Estimated.

Oxygen-Source/Sink

Area

Diffusive gas flux

Photosynthesis

Advection

Biol. decomposition

Tidal front

$\begin{array}{lc}\text { Boundary Pass } & 0.37 \text { (model } 0.1) \\ \text { all fronts } & 0.92(\text { model } 0.25)\end{array}$

Fraser Estuary

Strait of Georgia

$450 \mathrm{~km}^{2 * *)}$

6.5

5

?

?

$10.950 \mathrm{~km}^{2 *)}$

$115 / 68$

152

$-100$

$-150(?)$

0.72 (model $>0.1)$

1.8 (model $>0.25)$

Oxygen background values in the subsurface waters of the Strait of Georgia and Haro Strait are about $4.5 \mathrm{mLL}^{-1}$ (Fig. 2). The dense water in Haro Strait mixes at the sill with aerated surface water which has dissolved oxygen levels of about $5.5 \mathrm{~mL} \mathrm{~L}^{-1}$. This water mass is then advected to intermediate depths with oxygen values of $5.0 \mathrm{~mL} \mathrm{~L}^{-1}$, suggesting a 1:1 mixing ratio between both water masses. Additional oxygen is supplied by bubble entrainment in the tidal front. Due to the contribution of the tidal fronts, the oxygen concentration of the newly subducted intermediate water is increased by $0.08 \mathrm{~mL} \mathrm{~L}^{-1}$ (best guess).

\section{Discussion}

These results show that entrainment of gas bubbles in tidal fronts may contribute $\sim 8 \%$ to the aeration of intermediate water in the Strait of Georgia. This "best guess" represents a conservative estimate. The hydraulic sill flow at Boundary Pass delivers additional oxygen from the aerated surface waters in Haro Strait. In the following, the different processes relevant to entrainment of gas bubbles in tidal fronts will be reviewed together with the corresponding uncertainties.

The flow field of the tidal front is important because the surface convergence zone determines the point at which surface waves break, and hence the location of bubble injection. The injected bubbles are carried away by the subducting water. The currents determine the extent of gas dissolution from the bubbles and the depth to which the aerated water is carried. In this respect, the processes right at the sea surface are especially important. The currents are measured below $1 \mathrm{~m}$ depth and provide a good estimate of the current speed with which the gas bubbles are advected past the lower layer plunge point. The flow field may, however, be subject to seasonal or spring-neap tidal variations as the density difference across the front may change due to the Fraser River discharge or due to mixing. This is suggested by brief observations in January 2002 when the tidal front at Boundary Pass was much less pronounced because of weaker stratification with gas bubble clouds reaching only $40 \mathrm{~m}$. 
The gas pressure difference between water and bubble determines how much gas dissolves before the bubbles return to the sea surface. This is not critical, however, as the downwelling currents are stronger than the rise speed of the largest bubbles. We can therefore assume that all bubbles injected close to the plunge point dissolve. We may therefore limit our considerations to the void fraction rather than the actual bubble size distribution.

The void fraction is hard to estimate. Values in the literature range over two orders of magnitude, depending on the type of breaking wave. We have taken a value intermediate between plunging and spilling breakers, which means that the estimated contribution of tidal fronts to the aeration of an estuary could well be a factor of 10 larger or smaller. The size of the waves and the entrainment depth corresponding to the given void fraction (Loewen et al., 1996; Lamarre and Melville, 1991) is representative for calm conditions. Even then, waves break due to the effect of wave-current interaction. On windy days, however, the bubble entrainment depth and void fraction would increase and hence the amount of gas dissolved. Our estimate of $8 \%$ for the contribution to the aeration of intermediate water can therefore be considered to be conservative.

Bubble induced air-sea gas exchange in tidal fronts is also found in other coastal environments where strong tidal currents interact with a rugged topography. Data from the Strait of Messina, Italy (pers. comm. P. Brandt, IfM Kiel), Bay of Fundy (pers. comm. D. Johnston, Duke Marine Lab) and Gulf of St. Lawrence, Canada, show bubble entrainment to depths of 40 to $80 \mathrm{~m}$. This process is likely to occur also around places like Ireland, Norway, Chile, Japan, and in the North Sea. The importance of tidal fronts for the aeration of an estuary varies with the geographical setting. Air-sea gas exchange in tidal fronts is more important in estuaries with a small surface area and numerous and extended tidal fronts than in large estuaries with only a few fronts.

Surface convergence zones also form in Langmuir circulation (Thorpe and Stubbs, 1979; Thorpe, 1982) or during deep convection events in the North Atlantic and Mediterranean Sea in some winters (Schott et al., 1999). Downwelling currents are $5-15 \mathrm{~cm} \mathrm{~s}^{-1}$ and the associated divergence/convergence patterns may increase wave breaking and the formation and subduction of gas bubbles. In the latter case, gases like $\mathrm{O}_{2}$ are carried down to depths of more than $1500 \mathrm{~m}$ forming a direct connection between surface waters and the deep ocean.

Because of the limitations of the observations, it would be desirable to carry out additional measurements. In this respect, special focus should be given to near surface processes that are important for the gas exchange by bubbles. In particular, observations of void fraction or bubble size distribution in combination with measurements of surface currents and turbulence may help to understand the gas entrainment mechanisms in tidal fronts.

Acknowledgments. We gratefully acknowledge the support and cooperation of the officers and crew of CCGS Vector, which were essential in collecting data in a navigationally very challenging environment. We also thank Drs. Patrick Cummins, Rolf Lueck, and Eddy Carmack for their helpful suggestions and discussions which improved this study. Many thanks also to the Ocean Acoustics Group at the Institute of Ocean Sciences, Sidney, Canada, for the support during the project. This 
work is a part of research projects carried out with the support of the US Office of Naval Research and the Natural Sciences and Engineering Research Council of Canada.

\section{APPENDIX}

\section{Sensitivity of model results}

A sensitivity study is used to investigate the importance of single model parameters incorporated in the oxygen flux calculations. We take wave II approaching the front from the east and wave I approaching from the west as references (see Section 5), representing the waves contributing most to the aeration of subsurface waters. Additional model runs are carried out with one parameter changed at a time, so that the sensitivity can be studied (Table 4).

The diffusion of gas from a bubble to the surrounding water depends on the gas saturation in water. In this particular front, however, the gas saturation levels have little effect on gas flux. Due to the small entrainment depths, the bubbles either rise quickly back to the surface, so that an increased concentration difference has little effect, or they dissolve completely. For example, if the saturation of $\mathrm{O}_{2}$ in the water drops from $100 \%$ to $80 \%$, the total gas flux in the front increases by less than 3\%. In the Fraser Estuary, undersaturated conditions are predominant with the exception of the surface layer in the Strait of Georgia in summer. A saturation of $100 \%$ is therefore a slightly conservative value.

Table 4. Parameter values for the model calculations of gas entrainment in the tidal front at Boundary Pass. The lower part of the tables shows the results from the sensitivity study; values different to those of the reference runs (upper part of tables) are shown in bold letters.

$\longleftarrow$ Waves from the East

$\begin{array}{cccccc}\text { Wave } & \alpha & \delta[\mathrm{m}] & \sigma[\%] & \mathcal{E}[\%] & \mathrm{O}_{2} \text {-flux }\left[\mathrm{m}^{3} / \mathrm{s}\right] \\ \text { I } & -1.5 /-3.3 & a / 4 & 100 & 0.3 & 0 \\ \text { II } & -1.5 /-3.3 & a / 4 & 100 & 0.3 & 0.012 \\ \text { III } & -1.5 /-3.3 & a / 4 & 100 & 0.3 & 0.009 \\ \text { II } & \mathbf{- 2} & a / 4 & 100 & 0.3 & 0.011 \\ \text { II } & \mathbf{- 4 . 5} & a / 4 & 100 & 0.3 & 0.086 \\ \text { II } & -1.5 /-3.3 & \mathbf{a} & 100 & 0.3 & 0.003 \\ \text { II } & -1.5 /-3.3 & a / 4 & \mathbf{8 0} & 0.3 & 0.012 \\ \text { II } & -1.5 /-3.3 & a / 4 & 100 & \mathbf{3 0} & 1.17\end{array}$

$\longrightarrow$ Waves from the West

$\begin{array}{cccccc}\text { Wave } & \alpha & \delta[\mathrm{m}] & \sigma[\%] & \mathcal{E}[\%] & \mathrm{O}_{2} \text {-flux }\left[\mathrm{m}^{3} / \mathrm{s}\right] \\ \text { I } & -1.5 /-3.3 & a / 4 & 100 & 0.3 & 0.02 \\ \text { II } & -1.5 /-3.3 & a / 4 & 100 & 0.3 & 0 \\ \text { III } & -1.5 /-3.3 & a / 4 & 100 & 0.3 & 0.007 \\ \text { I } & \mathbf{- 2} & a / 4 & 100 & 0.3 & 0.018 \\ \text { I } & \mathbf{- 4 . 5} & a / 4 & 100 & 0.3 & 0.045 \\ \text { I } & -1.5 /-3.3 & \mathbf{a} & 100 & 0.3 & 0.005 \\ \text { I } & -1.5 /-3.3 & a / 4 & \mathbf{8 0} & 0.3 & 0.021 \\ \text { I } & -1.5 /-3.3 & a / 4 & 100 & \mathbf{3 0} & 2.03\end{array}$


The spectral slope of the bubble size distribution $\alpha$ determines the relative importance of small versus large bubbles. If we choose $\alpha=-2$ for the whole spectrum, there are more large bubbles in the water than in the reference run, the gas flux decreases by about $9 \%$ as the bubbles rise more quickly to the surface. The results are not sensitive to the choice of cut-off radius for large bubbles $r_{2}$. If there are more small bubbles $(\alpha=-4.5)$, the gas flux increases by a factor of 2 to 7 . The values for $\alpha$ used in the reference runs are therefore also a conservative choice.

For the reference runs, $\delta=a / 4$ has been chosen for the entrainment depth as it yields very similar results for void fraction and bubble size distribution to those of Loewen et al. (1996) for small spilling breakers. An entrainment depth of $\delta=a$, for example, would yield results that are 16 times smaller than those observations, assuming the same value for $\mathcal{E}$. It should be kept in mind though that the laboratory breaking mechanism involved a sloping boundary rather than a wave breaking on a current.

The number of injected bubbles is determined by the portion of energy $\mathcal{E}$, that goes into the subduction of gas bubbles. For our model runs, we have so far assumed a very low value of $\mathcal{E}=0.003$ (Loewen et al., 1996), which may be suitable for wave amplitudes of a few centimeters. For bigger waves, or if the breaking waves are plunging rather than spilling breakers, a higher value of $\mathcal{E}=0.3-0.5$ may be more appropriate (Lamarre and Melville, 1991). For $\mathcal{E}=0.3$, the resulting oxygen flux increases by a factor of 100 . If we increase the entrainment depth without increasing the amplitude, fewer bubbles are injected and the gas flux decreases. An increase of $\delta$ by a factor of 4 reduces the gas flux by $75 \%$.

\section{REFERENCES}

Armi, L. and D. M. Farmer. 2002. Stratified flow over topography: Bifurcation fronts and transition to the uncontrolled state. Proc. Roy. Soc., 458, A, 513-538.

Baldy, S. 1988. Bubbles in the close vicinity of breaking waves: statistical characteristics of the generation and dispersion mechanism. J. Geophys. Res., 93, C7, 8239-8248.

Baldy, S. and M. Bourguel. 1985. Measurements of bubbles in a stationary flow field of breaking waves by a laser-based single-particle scattering technique. J. Geophys. Res., 90, C1,1037-1047.

1987. Bubbles between the wave trough and wave crest levels. J. Geophys. Res., 92, C3, 29192929.

Baschek, B. 2003. Air-sea gas exchange in tidal fronts. PhD thesis, University of Victoria, 156 pp.

2005. Wave-current interaction in tidal fronts, in Proceedings 14th'Aha Huliko'a Winter Workshop 2005: Rogue Waves, P. Müller and C. Garrett, eds., 131-138.

Bretherton, F. P. and C. J. R. Garrett. 1969. Wavetrains in inhomogeneous moving media. Proc. Roy. Soc., 302, A, 529-554.

Bretschneider, C. L. 1958. Revisions in wave forecasting: deep and shallow water, Proceedings, 6th Conference on Coastal Engineering Council of Wave Research, University of California, Berkeley, 1-18.

Chanson, H. and L. Jaw-Fang. 1997. Plunging jet characteristics of plunging breakers. Coastal Eng., 31, 125-141.

Crawford, G. B. and D. M. Farmer. 1987. On the spatial distribution of ocean bubbles. J. Geophys. Res., 92, C8, 8231-8243. 
Crean, P. B. and A. B. Ages. 1971. Oceanographic records from twelve cruises in the Strait of Georgia and Juan de Fuca Strait. Dept. of Energy, Mines, and Resources, Marine Research Branch, 1-4, 389 pp.

Deane, G. B. 1997. Sound generation and air entrainment by breaking waves in the surf zone. J. Acoust. Soc. Am., 102, 2671-2689.

Deane, G. B. and M. D. Stokes. 1999. Air entrainment processes and bubble size distributions in the surf zone. J. Phys. Oceanogr., 29, 1393-1403.

2002. Scale dependence of bubble creation mechanisms in breaking waves. Nature, 418,839 844.

Donelan, M., M. S. Longuet-Higgins and J. S. Turner. 1972. Periodicity in whitecaps. Nature, 239, 449-451.

Duncan, J. H. 2001. Spilling breakers. Annu. Rev. Fluid Mech., 33, 519-547.

Fan, L.-S. and K. Tsuchiya. 1990. Bubble Wake Dynamics in Liquids and Liquid-Solid Suspensions, Butterworth-Heinmann, Stoneham, MA, 363 pp.

Fan, L.-S., G. Q. Yang, D. J. Lee, K. Tsuchiya and X. Luo. 1999. Some aspects of high-pressure phenomena of bubbles in liquids and liquid-solid suspensions. Chem. Eng. Science, 54, 4681-4709.

Farmer, D. M. and L. Armi. 1986. Maximal two-layer exchange over a sill and through the combination of a sill and contraction with barotropic flow. J. Fluid Mech., 164, 53-76.

— 1998. Stratified flow over topography: The role of small scale entrainment and mixing in flow establishment. Proc. Roy. Soc., 455, A, 3221-3258.

Farmer, D. M., E. A. D’Asaro, M. V. Trevorrow and G.T. Daikiri. 1995. Three-dimensional structure in a tidal convergence front. Cont. Shelf Res., 15, 1649-1673.

Farmer, D. M., R. Pawlowicz and R. Jiang. 2002. Tilting separation flows: a mechanism for intense vertical mixing in the coastal ocean. Dyn. Atmos. Ocean, 36, 43-58.

Farmer, D. M., S. Vagle and A. D. Booth. 1998. A free-flooding acoustical resonator for measurement of bubble size distributions. J. Atm. Oceanic Tech., 15, 1121-1146.

Galvin, C. J. 1968. Breaker type classification on three laboratory beaches. J. Geophys. Res., 73, 3651-3659.

Gargett, A. and J. Moum. 1995. Mixing efficiencies in turbulent tidal fronts: results from direct and indirect measurements of density flux. J. Phys. Oceanogr., 25, 2583-2608.

Garrett, C., M. Li and D. M. Farmer. 2000. The connection between bubble size spectra and energy dissipation rates in the upper ocean. J. Phys. Oceanogr., 30, 2163-2171.

Hwang, P. A., Y.-H. L. Hsu and J. Wu. 1990. Air bubbles produced by breaking wind waves: a laboratory study. J. Phys. Oceanogr., 20, 19-28.

Johnson, B. D. and R. C. Cooke. 1979. Bubble populations and spectra in coastal waters: a photographic approach. J. Geophys. Res., 84, C7, 3761-3766.

Keeling, R. F. 1993. On the role of large bubbles in air-sea gas exchange and supersaturation in the ocean. J. Mar. Res., 51, 237-271.

Kirke, J. T. O. 1994. Light and Photosynthesis in Aquatic Ecosystems. 2nd ed., Cambridge University Press, Cambridge, 525 pp.

Koblents-Mishke, O. I. 1965. Primary production in the Pacific Ocean. Oceanology, 2, 104-116.

Lamarre, E. and W. K. Melville. 1991. Air entrainment and dissipation in breaking waves. Nature, $351,469-472$.

LeBlond, P. H., H. Ma, F. Doherty and S. Pond. 1991. Deep and intermediate water replacement in the Strait of Georgia. Atmos. Oceans, 29, 288-312.

Liss, P. S. and L. Merlivat. 1986. Relationship between wind speed and gas exchange over the ocean, in The Role of Air-Sea Exchange in Geochemical Cycling, P. Buat-Menard, ed., D. Reidel, Hingham, MA, 113-129. 
Loewen, M. R., M. A. O’Dor and M. G. Skafel. 1996. Bubbles entrained by mechanically generated breaking waves. J. Geophys. Res., 101, C9, 20,759-20,769.

Longuet-Higgins, M. S. 1969. On wave breaking and the equilibrium spectrum of wind-generated waves. Proc. Roy. Soc., 310, A, 151-159.

Masson, D. 2002. Deep water renewal in the Strait of Georgia. Estuar. Coast. Shelf Sci., 54, 115-126.

Medwin, H. 1970. In situ acoustic measurements of bubble populations in coastal ocean waters. J. Geophys. Res., 75, 599-611.

Melville, W. K. and R. J. Rapp. 1985. Momentum flux in breaking waves. Nature, 317, 514-516.

Monahan, E. C. 1993. Occurrence and evolution of acoustically relevant sub-surface bubble plumes and their associated, remotely monitorable, surface whitecaps, in Natural Physical Sources of Underwater Sound, B. R. Kerman, ed., 503-517.

Müller, R. and P. Stadelmann. 2004. Fish habitat requirements as the basis for rehabilitation of euthropic lakes by oxygenation. Fish. Manag. Ecology, 11, 251-260.

Nepf, H. M., C. H. Wu and E. S. Chan. 1998. A comparison of two- and three-dimensional wave breaking. J. Phys. Oceanogr., 28, 1496-1510.

Pawlowicz, R. 2002. Observations and linear analysis of sill-generated internal tides and estuarine flow in Haro Strait. J. Geophys. Res., 107, C6,3056, doi:10.1029/2000JC000504.

Pawlowicz, R. and D. M. Farmer. 1998. Diagnosing vertical mixing in a two-layer exchange flow. J. Geophys. Res., 103, C13, 30,695-30,711.

Phillips, O. M. 1977. The Dynamics of the Upper Ocean, Cambridge University Press, 2nd ed., Cambridge, 344 pp.

Schott, F., M. Visbeck, U. Send, J. Fischer, L. Stramma and Y. Desaubies. 1999. Observations of deep convection in the Gulf of Lions, Northern Mediterranean, during the winter 1991/92. J. Phys. Oceanogr., 26, 505-524.

Thomson, R. E. 1994. Physical oceanography of the Strait of Georgia - Puget Sound - Juan de Fuca Strait system, in Review of the Marine Environment and Biota of Strait of Georgia, Puget Sound and Juan de Fuca Strait, Proc. BC/Washington Symp. on Mar. Env., R. Wilson, R. Beamish, F. Outkens and J. Bell, eds., 36-100.

Thorpe, S. A. 1982. On the clouds of bubbles formed by breaking wind-waves in deep water, and their role in air-sea gas transfer. Phil. Trans. R. Soc. Lond., A304, 155-210.

1984. A model of the turbulent diffusion of bubbles below the sea surface. J. Phys. Oceanogr., 14, 841-854.

1986. Measurements with an automatically recording inverted echo sounder; ARIES and the bubble clouds. J. Phys. Oceanogr., 16, 1462-1478.

Thorpe, S. A. and A. R. Stubbs. 1979. Bubbles in a freshwater lake. Nature, 279, 403-405.

Vagle, S. 1989. An acoustical study of the upper ocean boundary layer. PhD thesis, University of Victoria.

Wallace, D. W. R. and C. D. Wirick. 1992. Large air-sea gas fluxes associated with breaking waves. Nature, 356, 694-696.

Wanninkhof, R. 1992. Relationship between wind speed and gas exchange over the ocean. J. Geophys. Res., 97, C5, 7373-7382.

Woolf, D. K. and S. A. Thorpe. 1991. Bubbles and the air-sea exchange of gases in near-saturation conditions. J. Mar. Res., 49, 435-466.

$\mathrm{Wu}, \mathrm{C}$. H. and A. Yao. 2004. Laboratory measurements of limiting freak waves on currents. J. Geophys. Res., 109, C12002, doi:10.1029/2004JC002612. 